\title{
Recent advancements in optical fiber hydrogen sensors
}

\author{
Ya-nan Zhang ${ }^{1,2, *}$, Huijie Peng ${ }^{1}$, Xiaolong Qian ${ }^{1}$, Yuyan Zhang ${ }^{3}$, Guowen $\mathrm{An}^{1}$, Yong Zhao ${ }^{1,2}$ \\ ${ }^{1}$ College of Information Science and Engineering, Northeastern University, Shenyang \\ 110819, China \\ ${ }^{2}$ State Key Laboratory of Synthetical Automation for Process Industries, Shenyang 110819, \\ China \\ ${ }^{3}$ Shenyang Institute of Engineering, Shenyang 110136, China \\ *Corresponding author: zhangyanan@ise.neu.edu.cn
}

\begin{abstract}
A review for optical fiber hydrogen sensors based on palladium $(\mathrm{Pd})$ and tungsten oxide $\left(\mathrm{WO}_{3}\right)$ thin films is presented, with specific focus on the measurement methods, probe structures, and sensing properties of different sensors. Firstly, the theoretical models behind the optical fiber hydrogen sensors, as well as their practical limitations, are addressed. Secondly, four mainstream measurement methods, including intensity, fiber Bragg grating (FBG), interferometer, surface plasmon resonance (SPR), which have been proposed to sense the physicochemical properties variations of sensitive thin films when exposed to hydrogen, are reviewed. Then, the advantages and disadvantages of all the above measurement methods are also discussed and compared. Finally, the existing problems and future prospects of optical fiber hydrogen sensors are pointed out.
\end{abstract}

Keywords: Optical fiber sensor; Hydrogen sensor; Palladium; Tungsten oxide. 


\section{Introduction}

As a new energy of high efficiency, non-pollution, sustainability, and abundant availability, hydrogen plays an important role in solving the energy crisis at present [1]. Meanwhile, hydrogen is also the characteristic gas for fault diagnosis of power transformers [2]. Recently, hydrogen has been widely used in aerospace engineering, petroleum explorations, metallurgical refineries, cryogenic cooling, chemical processing, automobiles, and many other fields [3, 4]. However, hydrogen is also a highly flammable and explosive gas due to its high diffusion coefficient $(0.16$ $\mathrm{cm}^{2} / \mathrm{s}$ in air), low ignition energy $(0.018 \mathrm{~mJ})$, high combustion heat $(285.8 \mathrm{~kJ} / \mathrm{mol})$, and wide explosion concentration range $(4 \% \sim 75 \%)$. Therefore, it is potentially dangerous in the utilization, storing, or transportation of hydrogen [5].

To mitigate the risks of explosion or assess health statuses of transformers, it is needed to realize the high-sensitive, high-precision, rapid, robust, real-time, on-line, and long-distance monitoring of hydrogen concentration [6]. Therefore, many researches on developing high-performance hydrogen sensors have been stimulated in recent years [7], among which the optical fiber hydrogen sensors have become research hotpot due to their outstanding advantages, such as intrinsic safety, corrosion resistance, suitable for remote sensing, and immune to electromagnetic interference. Besides, the optical fiber hydrogen sensors are also applicable to the hazardous or foul environments since their sensing mediums are optical signal and there is no risk of spark or ignition in the sensing regions.

The typical probe structure of an optical fiber hydrogen sensor is relied on sensitive thin film coating on surface of optical fiber $[8,9]$. When surrounding hydrogen concentration is changed, the physicochemical characteristics of sensitive thin film will change according to certain relationship, and then induce the variations of optical signal that transmitted in the optical fiber, in terms of 
intensity, wavelength, and/or phase. As a result, the hydrogen concentration can be deduced by monitoring the variations of optical signals. Based on this sensing mechanism, a number of measurement methods of optical fiber hydrogen sensor have been proposed and demonstrated, including absorption intensity [10], fiber gratings [11], interferometers [12], and surface plasmon resonance (SPR) [13].

In this paper, an overview of optical fiber hydrogen sensors over recent years is introduced in detail, wherever available, to give some inspirations for further researches on other measurement methods of optical fiber hydrogen sensors. The rest of this paper is organized as follows: In section 2, the method principles of optical fiber hydrogen sensors are analyzed and discussed. In section 3, various measurement methods of optical fiber hydrogen sensors, along with their structures, sensing properties, advantages and disadvantages are presented. In section 4, the existing problems and future research directions of optical fiber hydrogen sensors are put forward. Finally in section 6, we draw a brief conclusion and prospect.

\section{Measurement Principle}

The main developing trends of optical fiber hydrogen sensors are based on two kinds of sensitive thin films, i.e. palladium (Pd)-based thin films and tungsten oxide $\left(\mathrm{WO}_{3}\right)$-based thin films, coating onto the tip or along the length of an optical fiber.

\subsection{Pd-based sensitive thin films}

As a hydrogen reactant, $\underline{P d}$ has particular appeal to hydrogen. When hydrogen appears near the Pd film, the molecular hydrogen $\left(\mathrm{H}_{2}\right)$ will be dissociated into atomic hydrogen $(\mathrm{H})$, which is characterized by a high dissociation rate. Then the hydrogen atoms will diffuse through the Pd film easily, and finally the Pd film will rapidly convert into a reversible palladium hydride $\mathrm{PdH}_{k}$, where $k$ 
represents the atomic ratio of $\mathrm{H}$ to Pd. The hydration of Pd can also be related to a crystallographic phase transition represented by $\alpha$ and $\beta$, which can be described as:

$$
(\alpha) \mathrm{Pd}+\frac{k}{2} \mathrm{H}_{2} \longleftrightarrow(\beta) \mathrm{PdH}_{k}
$$

From a physical standpoint, the crystallographic change of Pd leads to an increment in lattice parameter. Consequently, the volume of Pd film expands (up to 900 times) associated with a reduction in dielectric constant of Pd film. Besides, the larger the concentration of surrounding hydrogen is, the lower the dielectric constant of Pd film is. The relationship between hydrogen concentration $c$ and the dielectric constant $\varepsilon$ of Pd film can be expressed by the following equation:

$$
\varepsilon_{\mathrm{Pd}}(c)=h(c) \times \varepsilon_{\mathrm{Pd}}(0)
$$

where $\varepsilon_{\mathrm{Pd}}(c)$ is the dielectric constant of Pd film for concentration $c$ of hydrogen; $\varepsilon_{\mathrm{Pd}}(0)$ is the dielectric constant of Pd film in the absence of hydrogen, which equals to $3.24 ; h(c)$ is a nonlinear function. In Ref. [14], it is demonstrated that the values of $h(c)$ are 1.0 and 0.8 for hydrogen concentration of $0 \%$ and $4 \%$, respectively [14]. The results also show that the dielectric constant of $\underline{\text { Pd film will decrease with the increase of hydrogen concentration. }}$

By coating Pd film onto fiber surface, the variation of hydrogen concentration can alter the volume and dielectric constant of Pd, which will then induce the change of optical signals in terms of intensity, wavelength, and/or phase according to different sensor configurations. These changes can be monitored to deduce the variations of hydrogen concentration [15].

For optical fiber hydrogen sensor based on Pd film, in the processes of cyclic absorption and desorption of hydrogen, the Pd film is susceptible to mechanical damages, such as cracking, blistering, and delamination, caused by the lattice expansion. This so-called embrittlement effect has negative influences on the stability and sensitivity of optical fiber hydrogen sensors based on Pd 
film. Recent studies have demonstrated that doping some suitable metals such as $\mathrm{Ni}, \mathrm{Ag}, \mathrm{Y}$, and $\mathrm{Au}$ into pure Pd film can alleviate the phase transition and weaken the embrittlement effect to some extent. And then, the mechanical stability and repeatability of hydrogen sensor can be improved. However, in the doping process, it is also needed to synthetically consider other issues such as sensitivity and accuracy.

\section{2 $\mathrm{WO}_{3}$-based thin films}

$\mathrm{WO}_{3}$ is a transition metal oxide with wide bandgap from $2.60 \mathrm{eV}$ to $3.25 \mathrm{eV}$ and perovskite-like atomic configuration [16]. It has been reported that $\mathrm{WO}_{3}$ film will change its color from greenish yellow to blue when exposed to hydrogen, due to the chemical interaction between $\mathrm{WO}_{3}$ and hydrogen. This gasochromic effect makes $\mathrm{WO}_{3}$ possible to detect hydrogen. In addition, when the $\mathrm{WO}_{3}$ film is exposed to hydrogen environment, its optical properties, such as reflectance, transmittance, absorption ${ }_{2}$ and refractive index will be modulated, which is an ideal candidate for hydrogen detection [17]. However, this chemical interaction between $\mathrm{WO}_{3}$ and hydrogen is not strong enough due to that the $\mathrm{WO}_{3}$ film can also chemically interact with other gases, such as hydrogen sulfide and acetylene. Therefore, bulk $\mathrm{WO}_{3}$ film does not have selective sensitivity to hydrogen, which limits its application in hydrogen sensor. To resolve this problem, a common

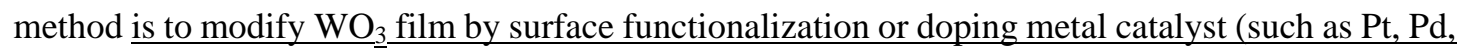

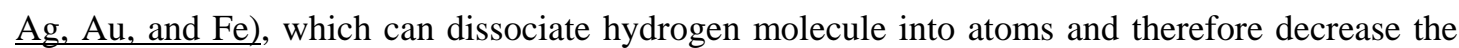
reaction activation energy $[18,19]$. With platinum $(\mathrm{Pt})$ as the catalyst, for example, the chemical reaction between the $\mathrm{Pt} / \mathrm{WO}_{3}$ film and surrounding hydrogen can be expressed as:

$$
\begin{gathered}
\mathrm{WO}_{3}+x \mathrm{H}_{2} \stackrel{\mathrm{Pt}}{\longrightarrow} \mathrm{WO}_{3-x}+x \mathrm{H}_{2} \mathrm{O} \\
\mathrm{WO}_{3-x}+\frac{x}{2} \mathrm{O}_{2} \stackrel{\mathrm{Pt}}{\longrightarrow} \mathrm{WO}_{3}
\end{gathered}
$$


When Pt is utilized as the catalyst, $\mathrm{WO}_{3}$ can drastically react with hydrogen and continuously generate heat when the hydrogen concentration is increased. Conversely, when the hydrogen concentration is decreased, the intermediate $\mathrm{WO}_{3-\mathrm{x}}$ will be oxidized and reform $\mathrm{WO}_{3}$. For constant hydrogen concentration, a thermal equilibrium can be established in the sensitive film, and finally a local temperature change can be generated near the optical fiber sensing probe. Therefore, one may obtain the value of hydrogen concentration by indirectly measuring the variation of temperature. In addition, the nanostructured $\mathrm{WO}_{3}$ film, including nano-particle, nano-rod, nano-wire, nano-platelet, or even nano-tree $[20,21]_{2}$ can be practically produced to obtain large surface to volume ratio and high electron mobility via dimensionality confined transport phenomena, resulting in a superior

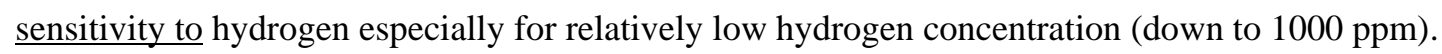

The optical fiber hydrogen sensor based on $\mathrm{WO}_{3}$ film owns superior advantages of high sensitivity and rapid respond, but its performances will be declined if there exist only little oxygen in ambient atmosphere. For some special facilities, such as nuclear waste tank, this sensor cannot work well. Besides, in the process of exothermic reaction, the ambient temperature can be increased to hundreds of Celsius under 4\% hydrogen concentration, which will increase the risk of hydrogen explosion. Therefore, the application range of this hydrogen sensor is restricted. To obtain optical fiber hydrogen sensor with rapid response rate and intrinsic safety, the increased temperature caused by $\mathrm{WO}_{3}$ film should not exceed the hydrogen's burning limit when hydrogen concentration is in the range of explosion.

\section{Measurement Methods}

From the above analyses, it can be found that both Pd-based film and $\mathrm{WO}_{3}$-based film are sensitive to hydrogen [22]. By coating these sensitive films on the surface of optical fiber, the 
optical signal will change with the variation of hydrogen concentration. Therefore, the hydrogen concentration can be on-line and long-distance monitored by measuring the transmitted or reflective optical signal. To overcome the potential problems that existed in hydrogen sensors based on the above sensitive films and further improve their sensing properties, many measurement methods have been proposed in recent years. For each measurement method, the structural configurations, working principle, sensing properties, advantages and disadvantages are reviewed in detail in the following.

\subsection{Intensity-based hydrogen sensor}

The measurement principle of intensity-based hydrogen sensor is that the light intensity will be changed with the variation of hydrogen concentration. According to the sensing mechanism, it can be classified into evanescent field sensor and micro-mirror sensor.

\subsubsection{Evanescent field sensor}

In practical application, evanescent field hydrogen sensor is so far the most common one. As shown in Fig. 1, the sensing region consists of an etched, tapered, or side-polished optical fiber and a layer of sensitive film coated on this core-exposed optical fiber. The etched optical fiber may be fabricated by destroying the cladding of conventional optical fiber through hydrofluoric acid corrosion or laser etching process, while the tapered optical fiber is mainly fabricated by splicing and tapering conventional optical fiber with a fusion machine, and the side-polished optical fiber is fabricated by mechanical polishing the cladding of conventional optical fiber.

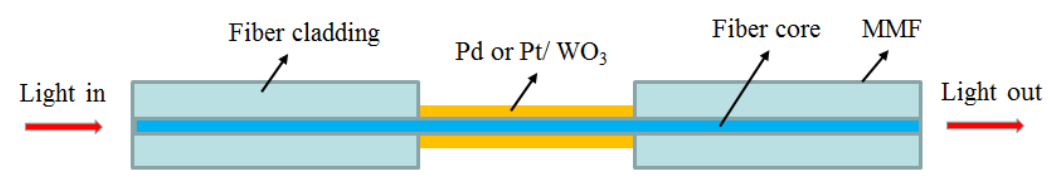

(a) Etched optical fiber 


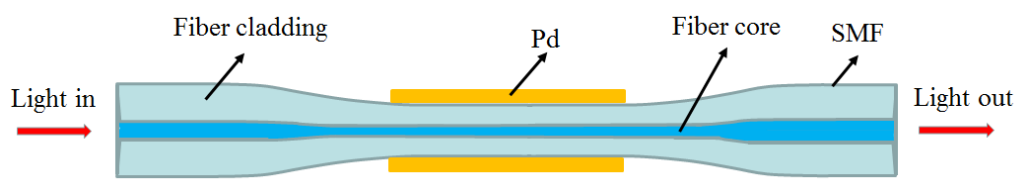

(a) Tapered optical fiber

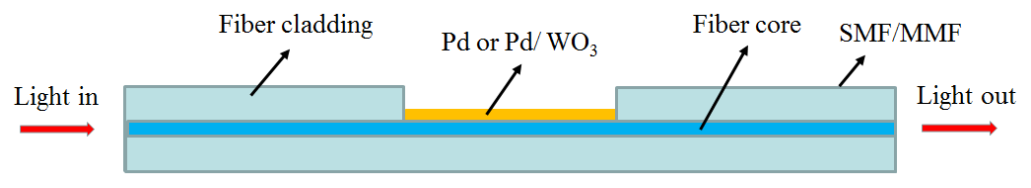

(a) Side-polished optical fiber

Fig. 1 Schematic probe structures of different optical fiber hydrogen sensors based on evanescent field

The sensing mechanism of evanescent field hydrogen sensor mainly relies on evanescent field

which appears at the junction of the core-exposed optical fiber and the sensitive film. The evanescent field decays exponentially with the increase of the distance from the optical fiber core, and the attenuation coefficient is mainly depend on the refractive index of fiber cladding. If fiber cladding is nearly or totally removed away, the sensitive film will act as the cladding, which can modify the evanescent field and therefore influence the transmitted light in fiber. Furthermore, when the sensing region is exposed to hydrogen, the refractive index of sensitive film will change, and then the evanescent field absorption, as well as the intensity of transmitted optical signal, will change along with the variation of surrounding hydrogen concentration. Therefore, the hydrogen concentration can be detected via monitoring the intensity of transmitted optical signal.

M. Tabib-Azar et al. [23] proposed the first evanescent field based optical fiber hydrogen sensor in 1999. The sensing head is constructed by depositing Pd film on an etched multimode fiber (MMF), as shown in Fig. 1(a). By using a $10 \mathrm{~nm}$ thickness $P d$ film with active interaction length of $1.5 \mathrm{~cm}$, the proposed sensor can detect hydrogen concentration in the range of $0.2 \%$ to $0.6 \%$ at room temperature, with corresponding response times of $30 \mathrm{~s}-20 \mathrm{~s}$.

Upon this structure, S. Sekimoto et al. [24] proposed a similar structure in 2000 but utilizing Pd or 
Pt doped $\mathrm{WO}_{3}$ film as the sensing cladding. Experimental results demonstrate that the absorption spectra of $\mathrm{Pt} / \mathrm{WO}_{3}$ thin film prepared by the sol-gel process is similar to the $\mathrm{Pd} / \mathrm{WO}_{3}$ in the silicone resin. Besides, it shows that the sensor with using the silicone resin-dispersed $\mathrm{Pd} / \mathrm{WO}_{3}$ has very slow response, but the response time will be significantly improved if the sol-gel process is introduced.

Latter in 2001, J. Villatoro et al. [25] demonstrated that the hydrogen concentration could also be realized by using a tapered single-mode fiber with Pd coating, as shown in Fig. 1(b). The sensing head is constructed with taper waist diameter of $25 \mu \mathrm{m}$, interaction length of $15 \mathrm{~mm}_{2}$ and Pd coating thickness of $12 \mathrm{~nm}$. Results demonstrate that the proposed sensor can be used to detect hydrogen concentration in the range of $1.8 \%$ to $10 \%$ at room temperature, and a maximum relative transmission increment of nearly $60 \%$ can be obtained for a $10 \%$ hydrogen concentration. In addition, the authors [26] further investigate the sensing properties of this sensor by changing the taper waist diameter, viz. $20 \mu \mathrm{m}, 25 \mu \mathrm{m}$, and $30 \mu \mathrm{m}$, but keeping the same interaction length and film thickness. Theoretical and experimental results demonstrate that the sensing sensitivity of this

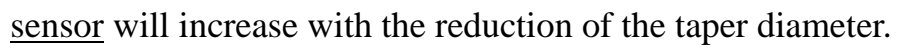

A few years later, K. T. Kim et al. [27] proposed another evanescent field hydrogen sensor based on a side-polished single mode fiber (SMF), as shown in Fig. 1(c), which was coated with a $40 \mathrm{~nm}$ thickness Pd film and embedded in a quartz fiber-holding circular groove. When exposed to $4 \%$ hydrogen gas, the output power of this sensor can be increased by as much as $1.2 \mathrm{~dB}$, with the rise time as short as $100 \mathrm{~s}$.

More recently, M. H. Yang et al. [28] further studied the evanescent field hydrogen sensor based on side-polished optical fiber. The polishing area $\underline{\text { is }} 10 \mathrm{~mm}$ in width, $\underline{58 \mu \mathrm{m}}$ and $32.5 \mu \mathrm{m}$ in depths 
for standard SMF and MMF, respectively. By comparing the hydrogen sensing performances and mechanical properties of Pd film coated side-polished SMF, Pd film coated side-polished MMF, $\mathrm{Pd} / \mathrm{WO}_{3}$ composite film coated side-polished $\mathrm{SMF}$, and $\mathrm{Pd} / \mathrm{WO}_{3}$ composite film coated side-polished MMF, the experimental results show that the transmitted intensities of sensors increase with hydrogen concentration for both SMF and MMF samples. However, for similar $\mathrm{Pd} / \mathrm{WO}_{3}$ composite film under the same hydrogen concentration variation, the intensity change of $\underline{\text { MMF based hydrogen sensor is greater than SMF one, while the response linearity of SMF based }}$ hydrogen sensor is much better than MMF sensor. As for MMF sensor, sample coated with $\mathrm{Pd} / \mathrm{WO}_{3}$ composite film has more than 10 times higher of response to hydrogen concentration variation than the sample coated with pure Pd film, while response is nearly 2 times higher in case of SMF sensor. Besides, $\mathrm{Pd} / \mathrm{WO}_{3}$ composite film presents much better mechanical reliability than pure Pd film.

From the above examples, it is demonstrated that light transmitted in the etched, tapered, or side-polished optical fiber (SMF or MMF) with sensitive film coating can generate evanescent field at the junction of fiber core and sensitive film, and the evanescent field absorption will change with the variation of surrounding hydrogen concentration. Therefore, the hydrogen concentration can be deduced by monitoring the transmitted intensity of light with using a low-cost broadband light source and a simple detector device. However, this core-exposed method may weak the strength of sensing head, and then influence the mechanical stability of hydrogen sensor. Besides, the output intensity signal is easily interrupted by external disturbances, which will then decrease the measurement accuracy and even make the sensor unable to work. The above potential problems prevent the practical applications of evanescent field hydrogen sensor to some extent. 


\subsubsection{Micro-mirror sensor}

Micro-mirror sensor is another commercially available sensor due to its quite simple structure. As shown in Fig. 2, it consists of a thin sensitive film that plated at the cleaved end of an optical fiber, and the thickness of sensitive film is in the range of $10 \mathrm{~nm} \sim 50 \mathrm{~nm}$. Its sensing mechanism relies on the Fresnel reflection phenomenon at the junction of optical fiber and sensitive film. When the sensor is exposed to hydrogen, the refractive index of sensitive film on the cleaved end of optical fiber will change, and then the reflective efficient of light that transmitted in the optical fiber will also change according to the principle of Fresnel reflection. Therefore, the hydrogen concentration can be detected via monitoring the intensity of reflective optical signal.

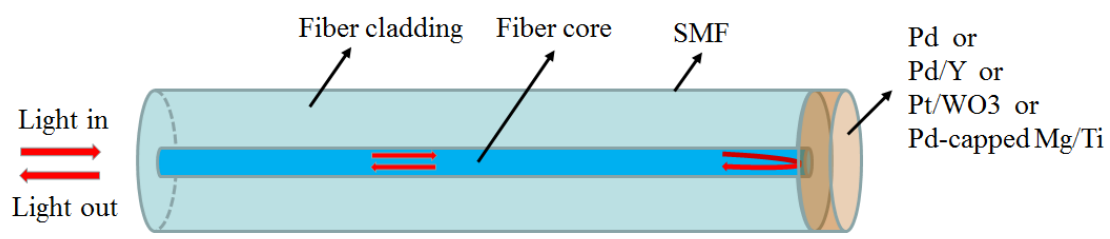

Fig. 2 Schematic probe structure of optical fiber hydrogen sensor based on micro-mirror

M. A. Butler et al. [29] proposed the first optical fiber micro-mirror hydrogen sensor in 1991. The

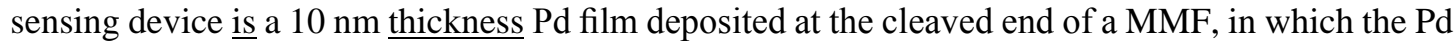
film is acted as a micro-mirror. When exposed to hydrogen at room temperature, the intensity of reflective light signal will decrease due to the refractive index reduction of Pd film. Then, due to the simple structure, the micro-mirror hydrogen sensor has been heavily studied with different improvements in recent years.

In 2012, Y. Liu et al. [30] proposed a dual-path micro-mirror hydrogen sensor based on $\mathrm{Pd} / \mathrm{Y}$ alloy film, which could eliminate noise interference caused by the fluctuation of light source, optical fiber loss, and temperature fluctuation, and therefore improve the signal to noise ratio of sensor. However, because the metal $\mathrm{Y}$ is easy to be oxidized, the hydrogen response will become slower 
after several months, which will destroy the long-term stability of hydrogen sensor. To resolve this

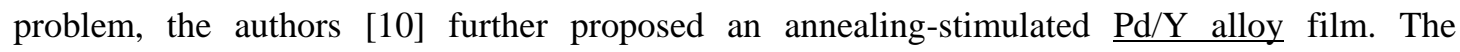
experimental results $\underline{\text { show }}$ that the response property and crystallinity of the $\mathrm{Pd} / \mathrm{Y}$ alloy film can be greatly enhanced after $200{ }^{\circ} \mathrm{C}$ thermal annealing.

Then in 2015, Z. Li et al. [31] proposed another dual-path micro-mirror hydrogen sensor based on $\mathrm{Pt} / \mathrm{WO}_{3}$ film, as shown in Fig. 3. As $\mathrm{WO}_{3}$ is a very stable oxide material, the proposed sensor shows good stability and repeatability. The experimental results show that the reflective intensity will decrease with the increase of hydrogen concentration. The response values of the sensor can reach to $86.8 \mathrm{mV}, 75 \mathrm{mV}, 67.6 \mathrm{mV}, 53.2 \mathrm{mV}, 48.3 \mathrm{mV}$ under hydrogen concentration of $4 \%, 1 \%, 0.5 \%$, $0.1 \%, 0.05 \%$, respectively.

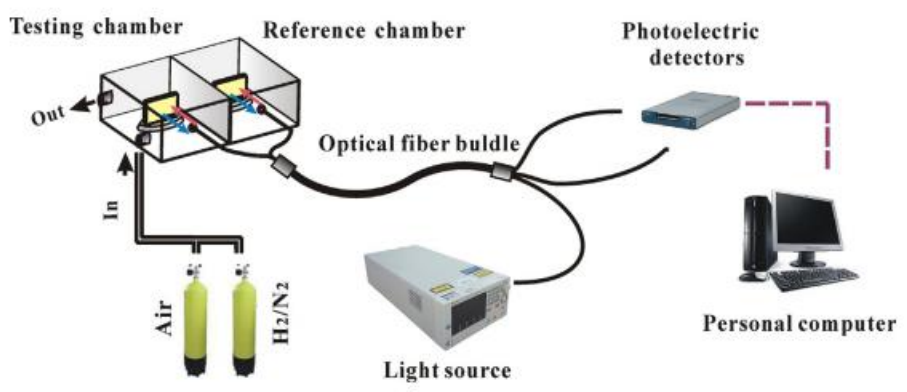

Fig. 3 Configuration of dual-path micro-mirror hydrogen sensor proposed by $\mathrm{Z}$. $\mathrm{Li}^{[30]}$

Besides, T. Mak et al. [32] introduced another sensitive film, namely, Pd-capped Mg-Ti thin film, for micro-mirror hydrogen. The proposed sensor can be used to detect and quantify the amount of dissolved hydrogen in transformer oil. With a $60 \mathrm{~nm}$ thickness $\mathrm{Mg}_{60} \mathrm{Ti}_{40}$ sensing layer, the proposed sensor enables us to measure the dissolved hydrogen concentration quantitatively between 5 ppm-15 ppm at $21{ }^{\circ} \mathrm{C}, 5 \mathrm{ppm}-30 \mathrm{ppm}$ at $40{ }^{\circ} \mathrm{C}, 5 \mathrm{ppm}-130 \mathrm{ppm}$ at $60{ }^{\circ} \mathrm{C}$, and $5 \mathrm{ppm}-1500 \mathrm{ppm}$ at

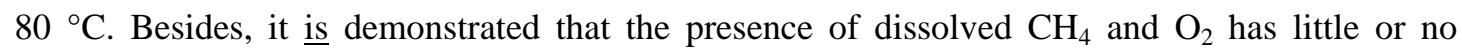
influence on the measured hydrogen concentration. But at high concentrations the oxygen will 
adversely affect the sensor's response due to a competitive water formation reaction.

In addition, to compensate the power fluctuation of optical source and mechanical perturbation in the fiber, a self-referencing technique was introduced in micro-mirror hydrogen sensor [33]. As shown in Fig. 4, the sensor head is composed of a dual-cavity, which is formed by splicing a hollow optical fiber (HOF) with two SMFs in series and coated with a Pd film only at the end of the fiber tip. Here, the length, inner diameter and outer diameter of $\mathrm{HOF}$ are $1.5 \mathrm{~mm}, 50 \mu \mathrm{m}$, and $125 \mu \mathrm{m}$, respectively. The free end of SMF is coated with nickel and Pd, whose thicknesses are $2 \mathrm{~nm}$ and 20 $\mathrm{nm}$, respectively. The $\mathrm{Pd}$ coating acts as the hydrogen sensitive film and the nickel coating acts as a buffer for better adhesion of the Pd. Based on three-beam interference model, the proposed technology can be well used to compensate the power fluctuation of light source and the loss perturbation of transmission fiber in the system.

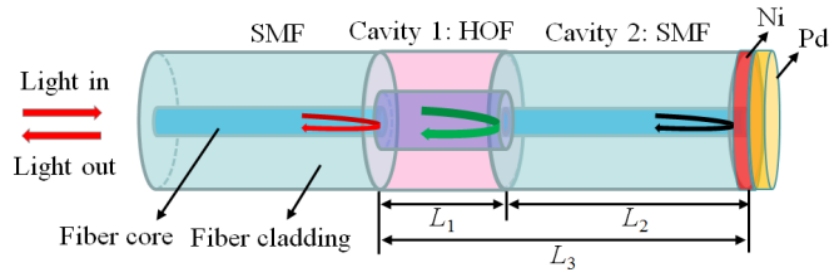

Fig. 4 Probe configuration of micro-mirror hydrogen sensor based on self-referencing technique ${ }^{[32]}$

Alternatively, S. J. Tang et al. [34] proposed another self-compensated micro-mirror hydrogen sensor. The dual-cavity is composed of an inner air-cavity and a collapsed photonic crystal fiber cavity. $\mathrm{WO}_{3}$ and Pt film act as the hydrogen transducer and catalyst, with thicknesses of $350 \mathrm{~nm}$ and $14 \mathrm{~nm}$, respectively. Experimental results show that the sensor has a short response time $(1 \mathrm{~min})$, good repeatability and reliability.

From the above examples, it is found that the sensing heads of micro-mirror hydrogen sensors are all reflective, which is very favorable for remote monitoring of hydrogen concentration. However, 
just like the evanescent hydrogen sensor, the potential problems of the essential intensity detection method are also existed in micro-mirror sensors. To eliminate the interferences, dual-path compensation $[30,31]$ and single-path self-compensation $[33,34]$ technologies are developed. However, in dual-path compensation technology, it is difficult to ensure the consistency and symmetry of the double channels, and thus will affect the measurement accuracy of hydrogen sensor. Besides, the sensing probe and corresponding chamber are adverse to miniaturization. On the other hand, the single-path self-compensation is easily to achieve miniaturization, but the fabrications of two cavities with accuracy cavity lengths are difficult and the structural parameters are hard to $\underline{\text { control. }}$

\subsubsection{Advantages and disadvantages}

The sensing performances and structures of various types of intensity-based optical fiber hydrogen sensors mentioned above are presented in Table 1.

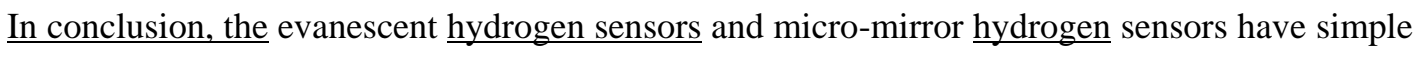
structure and low demand for optical devices, which can decrease the system cost and are more suitable for commercial applications. Besides, the specific reflective sensing head structure of micro-mirror sensor makes it possible for on-line and long-distance monitoring of hydrogen concentration. However, the essential intensity detection method makes the sensor easily susceptible to the fluctuations of light source and fiber loss. Although some improvement methods have been proposed, there is still a long way for intensity-based hydrogen sensors approaching widespread applications. Besides, there have not been effective solutions to improve the mechanical stability of evanescent hydrogen sensor.

Table 1. Performances comparison of intensity-based optical fiber hydrogen sensors 


\begin{tabular}{|c|c|c|c|c|c|}
\hline $\begin{array}{l}\text { Sensing } \\
\text { mechanism }\end{array}$ & Sensing head & $\begin{array}{l}\text { Sensitive film } \\
\text { (Thickness) }\end{array}$ & $\begin{array}{l}\text { Concentration } \\
\text { range }\end{array}$ & Response time & Ref \\
\hline \multirow{4}{*}{$\begin{array}{l}\text { Evanescent } \\
\text { field sensor }\end{array}$} & Etched MMF & $\mathrm{Pd}(10 \mathrm{~nm})$ & $0.2 \%-0.6 \%$ & $20 s-30 s$ & {$[23]$} \\
\hline & Etched MMF & $\mathrm{Pd}(\mathrm{Pt}) / \mathrm{WO}_{3}$ & $100 \%$ & $7 \mathrm{~min}$ & {$[24]$} \\
\hline & Tapered SMF & $\operatorname{Pd}(12 \mathrm{~nm})$ & $1.8 \%-10 \%$ & $<100 \mathrm{~s}$ & {$[25]$} \\
\hline & Side-polished SMF & $\operatorname{Pd}(40 \mathrm{~nm})$ & $4 \%$ & $<100 \mathrm{~s}$ & {$[27]$} \\
\hline \multirow{6}{*}{$\begin{array}{l}\text { Micro-mirr } \\
\text { or sensor }\end{array}$} & Cleaved end of MMF & $\mathrm{Pd}(10 \mathrm{~nm})$ & $4 \%$ & $150 \mathrm{~min}$ & [29] \\
\hline & $\begin{array}{l}\text { Dual-path optical fiber } \\
\text { bunble }\end{array}$ & $\mathrm{Pd} / \mathrm{Y}$ & $4.1 \%$ & $200 \mathrm{~s}-350 \mathrm{~s}$ & {$[30]$} \\
\hline & $\begin{array}{l}\text { Dual-path optical fiber } \\
\text { bunble }\end{array}$ & $\mathrm{Pt} / \mathrm{WO}_{3}$ & $0.05 \%-4 \%$ & $\begin{array}{l}1 \mathrm{~min}- \\
10 \mathrm{~min}\end{array}$ & {$[31]$} \\
\hline & Cleaved end of MMF & Pd-capped Mg-Ti $(60 \mathrm{~nm})$ & $5-1500 \mathrm{ppm}$ & -- & {$[32]$} \\
\hline & SMF-HOF-SMF & $\begin{array}{l}\mathrm{Ni}(2 \mathrm{~nm})- \\
\mathrm{Pd}(20 \mathrm{~nm})\end{array}$ & $4 \%$ & $65 \mathrm{~s}$ & {$[33]$} \\
\hline & $\begin{array}{l}\text { Air cavity and a collapsed } \\
\text { PCF }\end{array}$ & $\begin{array}{l}\mathrm{Pt}(15 \mathrm{~nm})- \\
\mathrm{WO}_{3}(350 \mathrm{~nm})\end{array}$ & $10 \%-30 \%$ & $1 \mathrm{~min}$ & {$[34]$} \\
\hline
\end{tabular}

\subsection{Fiber grating-based hydrogen sensor}

Fiber grating is a periodic structure aimed at refractive index modulation with a constant modulation period in the core of an optical fiber. According to the difference of modulation period, the fiber grating can be classified into fiber Bragg grating (FBG) with a period less than $1 \mu \mathrm{m}$ and long period grating (LPG) with a period in the range of $10 \mu \mathrm{m}$ to $100 \mu \mathrm{m}$. The sensing mechanism of FBG based hydrogen sensor relies on that the variation of strain or temperature induced by the chemical interaction between hydrogen and the sensitive coating shifts the Bragg wavelength. On the other hand, the sensing mechanism of LPG based hydrogen sensor relies on the coupling between the cladding modes and the evanescent waves. As shown in Fig. 5, when Pd sensitive thin film, for example, is coated on the surface of FBG or LPG, the resonant wavelength will shift along with the variation of hydrogen concentration. 


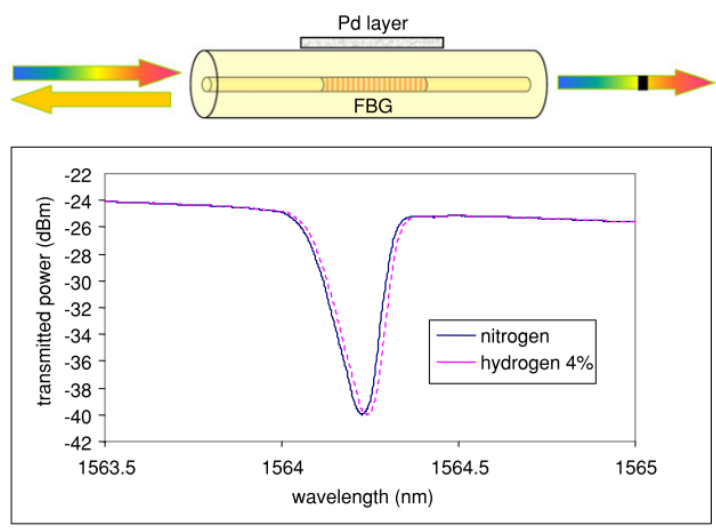

(a) Structure and transmission spectrum of FBG
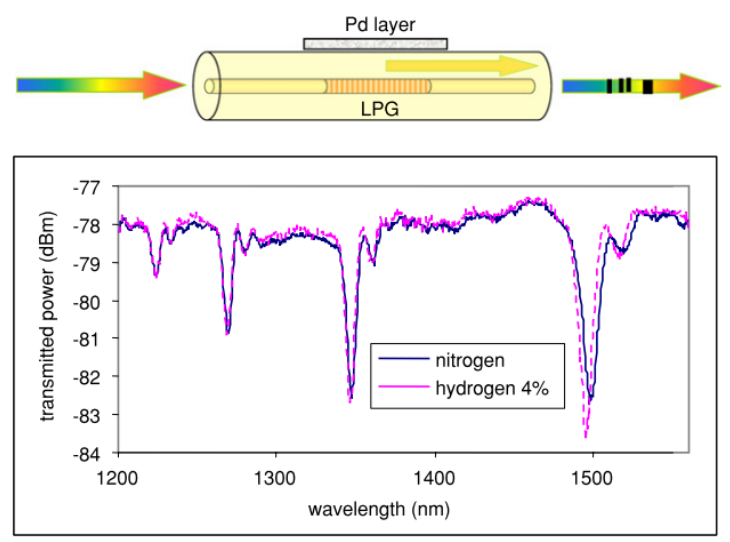

(b) Structure and transmission spectrum of LPG

Fig. 5 Structure schematics and transmission spectra of FBG and LPG coated with Pd film

\subsubsection{FBG-based sensor}

FBG-based hydrogen sensor monitors the central wavelength shift of reflected Bragg spectrum by allowing broadband light signal into the fiber. The reflected wavelength $\left(\lambda_{\mathrm{B}}\right)$ of the FBG is depend on its effective refractive index ( $\left.n_{\text {eff }}\right)$ and grating pitch $(\Lambda)$, which can be expressed as:

$$
\lambda_{\mathrm{B}}=2 n_{\mathrm{eff}} \Lambda
$$

When coating sensitive film onto the FBG, the volume expansion of Pd-based sensitive film or exothermic reaction of $\mathrm{WO}_{3}$-based sensitive film in the presence of hydrogen will all induce strain or temperature variation in the underlying FBG, which will then change the grating pitch and effective refractive index of the FBG due to the elasto-optic and thermo-optic properties of optical fiber, and finally cause the Bragg wavelength shift of the FBG:

$$
\Delta \lambda_{\mathrm{B}}=\lambda_{\mathrm{B}} \cdot[f(T, C)+g(\varepsilon, C)] \cdot C
$$

where $f(T, C)$ is a nonlinear function, which represents the temperature sensitivity coefficient of central wavelength to hydrogen concentration, and $g(\varepsilon, C)$ is a nonlinear function, which represents $\underline{\text { the strain sensitivity coefficient of central wavelength to hydrogen concentration. For one hydrogen }}$

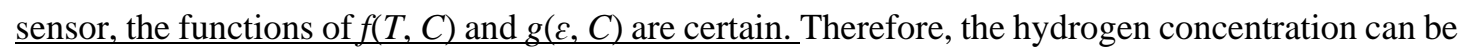
deduced by measuring the wavelength shift of the FBG. 
The first FBG-based hydrogen sensor was reported by Sutapun et al. in 1999 [35]. As shown in Fig. 6(a), the sensing head is a FBG coated with Pd thin film. The stress in the Pd coating stretches and shifts the Bragg wavelength of the FBG. Results demonstrate that the Bragg wavelength $\underline{\text { increases almost linearly as a function of hydrogen concentrations in the range of } 0.3 \%-1.8 \% \text {, with }}$ sensitivity of $1.95 \times 10^{-2} \mathrm{~nm} / \%$. Besides, many hydrogen sensors can be multiplexed on a single optical fiber by using FBGs with different resonant wavelengths.

However, due to the significant difference in volume between the sensitive film with a thickness of tens of nanometers and the optical fiber with diameter of $125 \mu \mathrm{m}$, the induced wavelength shift of FBG is relatively small, which results in a relatively low measurement sensitivity of hydrogen concentration. Therefore, from then on, many methods have been proposed to improve the measurement sensitivity of FBG-based hydrogen sensor.

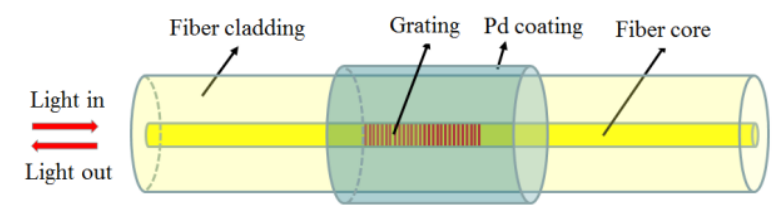

(a) FBG

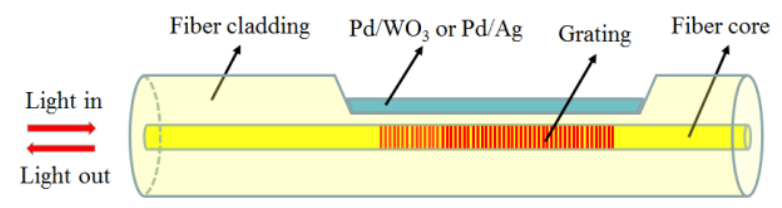

(b) Side-polished FBG

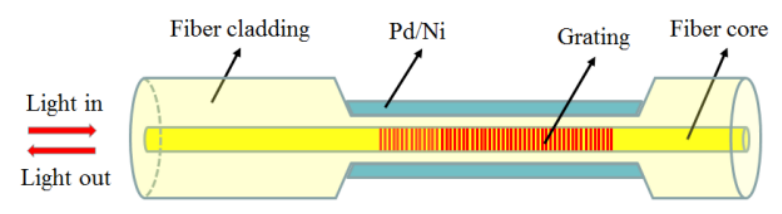

(c) Etched FBG

Fig. 6 schematic probe structures of different optical fiber hydrogen sensors based on FBG

The first one, perhaps the most common, is side-polished FBG. Since side-polished cladding is very sensitive to curvature strain induced by $\mathrm{Pd}$ in the presence of hydrogen, the proposed sensor is much more sensitive than the untreated FBG hydrogen sensor. In 2011, J. Dai et al. [36] proposed a 
side-polished FBG hydrogen sensor with $\mathrm{WO}_{3}-\mathrm{Pd}$ composite film, in which $\mathrm{WO}_{3}$ was deposited on the basal layer for its good adhesion toward fiber, Pd in the outmost layer was used as hydrogen sensitive film duo to its high sensitivity and selectivity to hydrogen, and $\mathrm{WO}_{3} / \mathrm{Pd}$ composite film was acted as intermediate layer to overcome material properties' mismatch of $\mathrm{WO}_{3}$ and $\mathrm{Pd}$. For polishing depth of $59 \mu \mathrm{m}$ and composite film thickness of $110 \mathrm{~nm}$, the maximum wavelength shifts of $25 \mathrm{pm}$ and $55 \mathrm{pm}$ are observed when hydrogen concentrations are $4 \%$ and $8 \%$, respectively.

Similarly, in 2015, J. Jiang et al. [37] also demonstrated a side-polished FBG hydrogen sensor with $\mathrm{Pd} / \mathrm{Ag}$ composite film. In the sensor design, the FBG cladding is side-polished with a residual thickness of $20 \mu \mathrm{m}$ and sputtered with Pd/Ag. Meanwhile, the authors have also demonstrated its possibility for monitoring dissolved hydrogen concentration in power transformer oil.

While in 2012, J. Dai et al. [38] proposed another hydrogen sensor by using a greatly etched fiber Bragg grating coated with Pd/Ni composite film. During the hydrogen response experiment, central wavelength shift of the etched FBG increases linearly with the increase of hydrogen concentration. When the hydrogen concentration is $4 \%$ in volume ratio, the wavelength shift of the etched FBG is about $60 \mathrm{pm}$, and the hydrogen sensor is not sensitive to methane.

To further enhance the sensitivity of this proposed sensor, the authors then deposited $\mathrm{Pd} / \mathrm{Ni}$ composite film on side-face of etched FBG and surface of polypropylene substrate [39]. The polypropylene sheet is employed as protective substrate, whose width and thickness are $3 \mathrm{~mm}$ and $0.1 \mathrm{~mm}$, respectively. Due to the much lower Young's modulus of polypropylene substrate, the measurement sensitivity is significantly improved, and showing $146 \mathrm{pm}$ wavelength shift towards $4 \%$ hydrogen. Similarly, the authors have demonstrated that the etched FBG with Pd/Ag composite film could also be used for hydrogen sensing [40]. 
As for the etched FBG, L. Coelho et al. [41] has cascaded two etched FBGs with diameter of 50 $\mu \mathrm{m}$ in one fiber. As shown in Fig. 7, one of the FBG on the left is uncoated, and the other one on the right is coated with $\mathrm{Pd}$ of $150 \mathrm{~nm}$. Considering that the $\mathrm{PdH}_{k}$ has unstable behavior in environments with high humidity level, the coated sensing device is protected between two thin commercial PTFE Teflon membranes with $20 \mu \mathrm{m}$ thickness, which are fixed by two aluminum plates. The Teflon layer

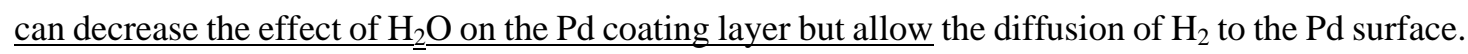
As a result, the proposed sensing device is able to respond to $\mathrm{H}_{2}$ concentration in the range of $0 \%-1 \%$ at room temperature and atmospheric pressure, achieving sensitivity large than $20 \mathrm{pm} / \%$.

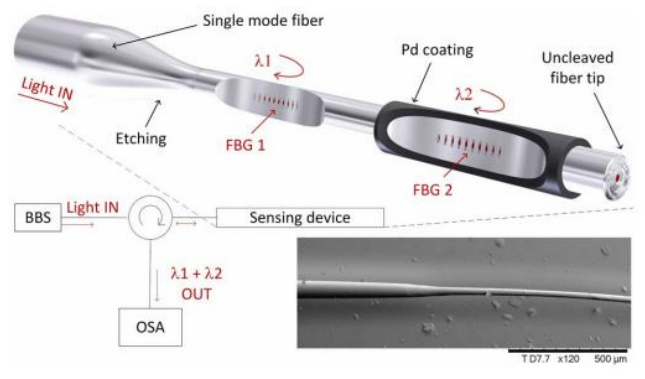

(a) Schematic structure of sensor

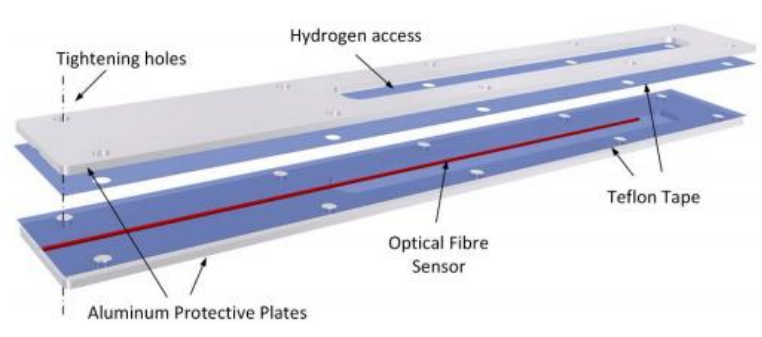

(b) Specific structure of sensor probe

Fig. 7 Configuration of optical fiber hydrogen sensor based on two cascaded and etched FBGs

However, it should be mentioned that the etched FBG is very fragile, making it not suitable for practical application. To maintain the mechanical stability and hydrogen sensitivity of sensitive film coated FBG, M. H. Yang et al. [42] proposed a novel FBG hydrogen sensor, which was prepared by combining the performance-improved Pt-loaded $\mathrm{WO}_{3}$ coating with temperature sensitivity-enhanced FBG structure. Firstly, the Pt-loaded $\mathrm{WO}_{3}$ coating is previously annealed at $315{ }^{\circ} \mathrm{C}$ for $1 \mathrm{~h}$, so the FBG hydrogen sensor can respond to lower concentration of hydrogen. Secondly, the FBG sensor is encapsulated in a glass matrix strip, which has a much higher thermal expansion coefficient, and the grating section of FBG is positioned in the slim groove of the glass matrix strip for depositing Pt-loaded $\mathrm{WO}_{3}$ coating. Therefore, the temperature sensitivity of FBG 
can be greatly increased. Besides, to enhance the stability of FBG, the $\mathrm{FBG}$ is annealed at $100{ }^{\circ} \mathrm{C}$ for 24 h. Experimental results demonstrate that the proposed FBG hydrogen sensor has 448 pm wavelength shift towards $8000 \mathrm{ppm}$ hydrogen concentration at room temperature of $25^{\circ} \mathrm{C}$, and it can detect hydrogen concentration as low as $200 \mathrm{ppm}$.

At the same time, the authors [43] shown that the response ability of hydrogen sensor based on

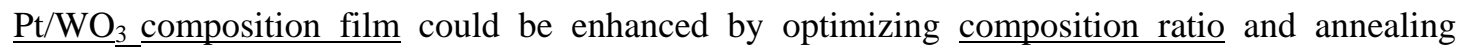

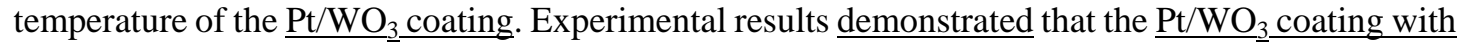
molar ratio of $1: 5$ and annealing temperature of $315^{\circ} \mathrm{C}$ owns the best sensitivity. The corresponding hydrogen sensor has $536 \mathrm{pm}$ wavelength shift towards $10000 \mathrm{ppm}$ hydrogen under room temperature of $25^{\circ} \mathrm{C}$. Besides, the ambient humidity has less effect on its performances, due to that

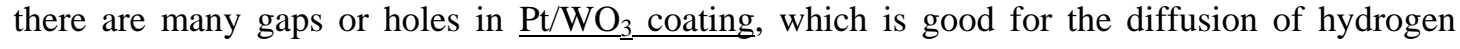
molecules, but water molecules cannot diffuse in all of these poles or gaps.

Then in 2015, J. M. Karanja et al. [44] proposed a micro-structured femtosecond laser assisted FBG hydrogen sensor, as shown in Fig. 8. The sensing head is fabricated by 3D laser machining on the fiber cladding to form multiple periodic micro-grooves and sputtered with $\mathrm{Pd} / \mathrm{Ag}$ composite film. At room temperature, the hydrogen sensitivity of the sensor is $16.5 \mathrm{pm}$ for $1 \%$ hydrogen concentration, with $75 \mathrm{~mW}$ laser power and $520 \mathrm{~nm}$ thickness $\mathrm{Pd} / \mathrm{Ag}$ film. Additionally, it was demonstrated that the increased number of micro-grooves and film thickness can improve the hydrogen sensitivity.
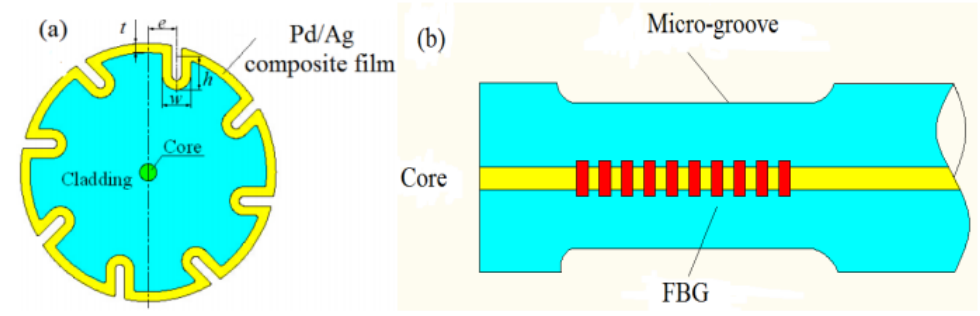

(a) Profile face diagram
(b) Side diagram

Fig. 8 Schematic probe structure of micro-structured femtosecond laser assisted FBG hydrogen sensor probe

Besides the side-polished FBG and etched FBG, in 2013 S. Silva et al. [45] demonstrated that the tapered FBG coated with $150 \mathrm{~nm}$ thickness $\mathrm{Pd}$ film could also be used for hydrogen measurement. The sensitivity becomes higher by reducing the fiber diameter, because the evanescent-field interaction is stronger for thinner microfiber. As shown in Fig. 9, the FBG is written in a 50- $\mu \mathrm{m}$-diameter tapered fiber by deep ultraviolet femtosecond laser technology. Besides, a second FBG is inscribed in the $125 \mu \mathrm{m}$-diameter conventional fiber for temperature compensation. The

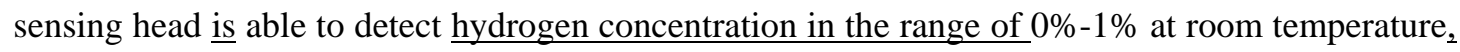
and a maximum sensitivity of $81.8 \mathrm{pm} / \%$ is attained with temperature compensation.

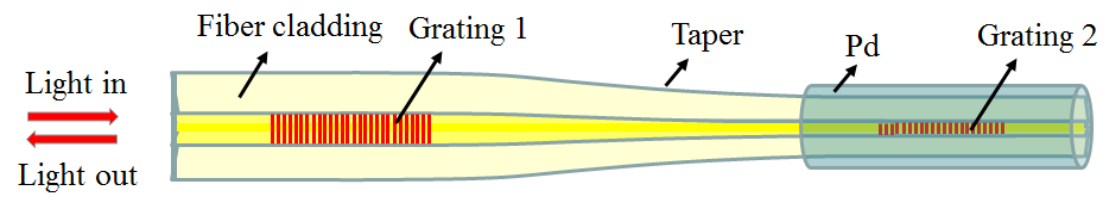

Fig. 9 Schematic probe structure of optical fiber hydrogen sensor based on tapered FBG

In 2015, the tapered FBG was further investigated by Z. P. Yu et al. [46]. As shown in Fig. 10, a microfiber FBG is fabricated in MMF with a diameter of only $3.3 \mu \mathrm{m}$. As a result, when exposed to hydrogen with a concentration of $5 \%$, a maximum wavelength shift of $-1.08 \mathrm{~nm}$ is achieved with $\mathrm{Pd}$ coating thickness of only $15 \mathrm{~nm}$. In principle, the thinner the fiber diameter, the higher sensitivity $\underline{\text { the hydrogen sensor. However, it should be mentioned that the excessive reduction of fiber diameter }}$ will decrease the mechanical stability of sensor.

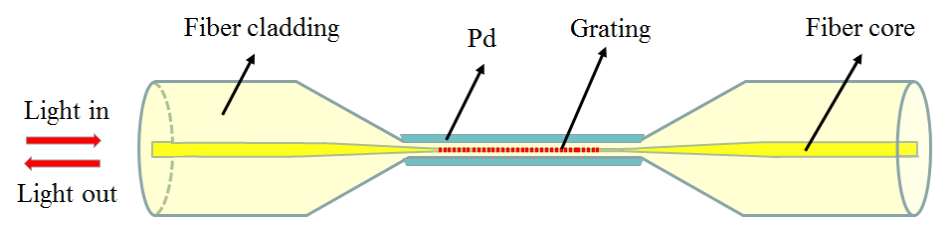

Fig. 10 Schematic probe structure of optical fiber hydrogen sensor based on tapered microfiber FBG

Actually, the FBG hydrogen sensor is more suitable for the distributed measurement due to its 
wavelength multipliable capability, and can be used for temperature compensation. Besides, in recent years it has been demonstrated that the FBG-based hydrogen sensor could be well used for fault detection of power transformer oil [47-49].

\subsubsection{LPG-based sensor}

In LPG, the fundamental core mode and multiple cladding modes exist and propagate in the same direction. The optical coupling between the fundamental core mode and the discrete cladding modes results in an uneven transmission spectrum of the $\underline{\mathrm{LPG}}$ which contains a series of attenuation bands centered at discrete wavelengths, namely resonant wavelength $\lambda$ (wavelength at minimum

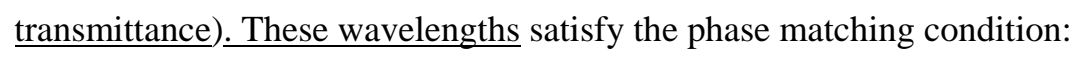

$$
\lambda=\Delta n_{\mathrm{eff}} \Lambda=\left(n_{\mathrm{co}}-n_{\mathrm{cl}, \mathrm{m}}\right) \Lambda
$$

where $\Lambda$ is the grating period. $n_{\mathrm{co}}$ and $n_{\mathrm{cl}, \mathrm{m}}$ are the effective indexes of the core and the $\mathrm{m}$-th order cladding mode, respectively. The $n_{\mathrm{cl}, \mathrm{m}}$ is readily affected by the refractive index of the material surrounding the cladding, which results in the shift of the resonant wavelength.

The interaction between sensitive film and hydrogen will change the effective index difference between the core and the cladding modes. Eventually, the variations of resonant wavelengths in the

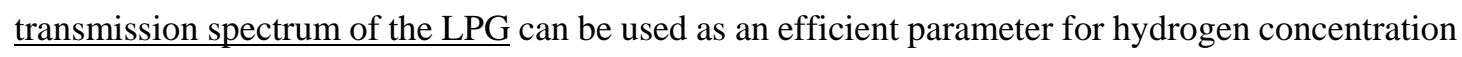
sensing.

In 2006, Trouillet et al. [50] proposed the first LPG-based hydrogen sensor. As shown in Fig. 11, the Pd layer with thickness of $50 \mathrm{~nm}$ is only coated on one side of the LPG through a $3 \mathrm{~cm}$ length mask centred on the grating. When hydrogen concentration is $4 \%$ in volume ratio, a wavelength shift of $\underline{5 \mathrm{~nm}}$ and $7 \mathrm{~nm}$ are obtained for the two wavelength resonance peaks at room temperature. Compared to the FBG-based sensor with similar structure, the sensitivity is enhanced by a factor up 
to 500 .

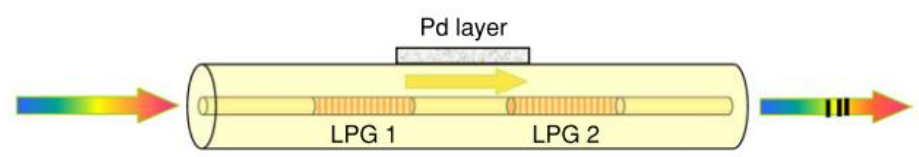

Fig. 11 Schematic probe structure of optical fiber hydrogen sensor based on two cascaded LPGs

Then in 2008, X. T. Wei et al. [51] proposed a Pd coated LPG for detecting of hydrogen concentration at temperature ranging from $30{ }^{\circ} \mathrm{C}$ to $200{ }^{\circ} \mathrm{C}$. The grating is $500 \mu \mathrm{m}$ in period and 6 $\mathrm{cm}$ in length. For Pd thickness of $70 \mathrm{~nm}$, the resonant wavelength can shift about $0.65 \mathrm{~nm}$ when exposed to $4 \%$ hydrogen at $100{ }^{\circ} \mathrm{C}$, and the response time of the proposed sensor is less than $3 \mathrm{~s}$.

Latter in 2011, Y. H. Kin et al. [52] also proposed a hydrogen sensor composed of a Pd-coated LPG, as shown in Fig. 12. It should be mentioned that the low core index fiber is used to excite high order cladding modes which are quite sensitive to the external refractive index change. The LPG has $400 \mu \mathrm{m}$ of grating period and $40 \mathrm{~mm}$ of grating length. With $70 \mathrm{~nm}$ thickness $P d$ coating over one side of the cladding surface, a $7.5 \mathrm{~nm}$ of the hydrogen-induced spectral shift is achieved when exposed to $4 \%$ hydrogen. The spectral response of the proposed sensor to hydrogen and its recovery with nitrogen are $176 \mathrm{~s}$ and $395 \mathrm{~s}$, respectively.

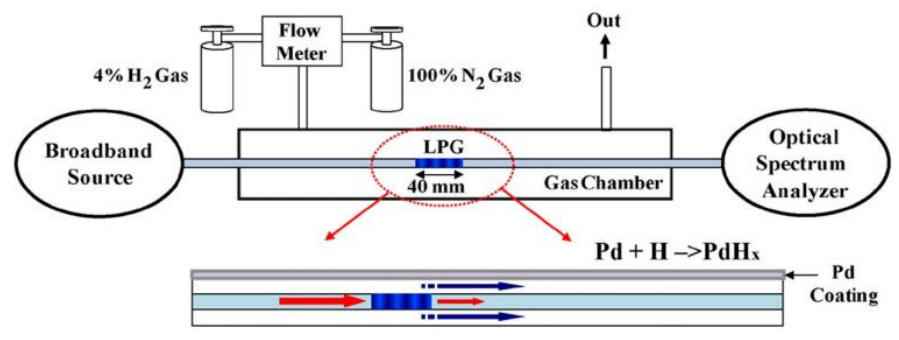

Fig. 12 Schematic probe structure of optical fiber hydrogen sensor based on one LPG

\subsubsection{Advantages and disadvantages}

The sensing performances and structures of various types of fiber grating-based optical fiber hydrogen sensors mentioned above are presented in Table 2. 


\begin{tabular}{|c|c|c|c|c|c|c|}
\hline $\begin{array}{l}\text { Sensing } \\
\text { mechanism }\end{array}$ & Sensing head & $\begin{array}{l}\text { Sensitive film } \\
\text { (Thickness) }\end{array}$ & $\begin{array}{l}\text { Concentration } \\
\text { range }\end{array}$ & Sensitivity & $\begin{array}{l}\text { Response } \\
\text { time }\end{array}$ & Ref \\
\hline \multirow{9}{*}{ FBG } & $\begin{array}{l}\text { Side-polished } \\
\text { FBG }\end{array}$ & $\mathrm{Pd} / \mathrm{WO}_{3}(110 \mathrm{~nm})$ & $8 \%$ & $6.5 \mathrm{pm} / \%$ & $<2 \min$ & {$[36]$} \\
\hline & $\begin{array}{l}\text { Side-polished } \\
\text { FBG }\end{array}$ & $\mathrm{Pd} / \mathrm{Ag}(400 \mathrm{~nm})$ & $0.08 \%$ & $4770 \mathrm{pm} / \%$ & $<1 \mathrm{~h}$ & {$[37]$} \\
\hline & Etched FBG & $\mathrm{Pd} / \mathrm{Ni}(110 \mathrm{~nm})$ & $4 \%$ & $15 \mathrm{pm} / \%$ & 4-5 $\min$ & {$[38]$} \\
\hline & $\begin{array}{l}\text { Etched FBG with } \\
\text { polypropylene } \\
\text { substrate }\end{array}$ & $\mathrm{Pd} / \mathrm{Ni}(100 \mathrm{~nm})$ & $0.5 \%-4 \%$ & $36.5 \mathrm{pm} / \%$ & $5-6 \min$ & {$[39]$} \\
\hline & Two etched FBGs & $\mathrm{Pd}(150 \mathrm{~nm})$ & $1 \%$ & $20 \mathrm{pm} / \%$ & $2 \mathrm{~min}$ & {$[41]$} \\
\hline & $\begin{array}{l}\text { FBG encapsulated } \\
\text { in a glass matrix } \\
\text { strip }\end{array}$ & $\mathrm{Pt} / \mathrm{WO}_{3}(50 \mathrm{~nm})$ & $0.02 \%-0.8 \%$ & $560 \mathrm{pm} / \%$ & $2 \mathrm{~min}$ & {$[42]$} \\
\hline & $\begin{array}{l}\text { Micro-structured } \\
\text { FBG }\end{array}$ & $\mathrm{Pd} / \mathrm{Ag}(520 \mathrm{~nm})$ & $0-4 \%$ & $16.5 \mathrm{pm} / \%$ & $10 \mathrm{~min}$ & {$[44]$} \\
\hline & Tapered FBG & $\mathrm{Pd}(150 \mathrm{~nm})$ & $0-1 \%$ & $81.8 \mathrm{pm} / \%$ & - & {$[45]$} \\
\hline & Tapered FBG & $\operatorname{Pd}(15 \mathrm{~nm})$ & $5 \%$ & $216 \mathrm{pm} / \%$ & $1 \mathrm{~min}$ & {$[46]$} \\
\hline \multirow{3}{*}{ LPG } & One side of LPG & $\mathrm{Pd}(50 \mathrm{~nm})$ & $4 \%$ & $1.75 \mathrm{pm} / \%$ & $2 \mathrm{~min}$ & {$[50]$} \\
\hline & LPG & $\mathrm{Pd}(70 \mathrm{~nm})$ & $4 \%$ & $162.5 \mathrm{pm} / \%$ & $70 \mathrm{~s}$ & {$[51]$} \\
\hline & LPG & $\mathrm{Pd}(70 \mathrm{~nm})$ & $4 \%$ & $1875 \mathrm{pm} / \%$ & $176 \mathrm{~s}$ & {$[52]$} \\
\hline
\end{tabular}

Due to the wavelength multipliable capability and reflective signal output of FBG, the

FBG-based hydrogen sensors show many unique advantages, such as: more suitable for the distributed measurement, favorable for remote sensing, easy for temperature compensation, and immune to the intensity fluctuation caused by optical source fluctuation and fiber loss. Therefore, the measurement accuracy of FBG-based hydrogen sensor is relatively good. But like the intensity-based hydrogen sensor, it is needed to reduce the external diameter of the fiber so as to improve the sensor's accuracy, which will also weaken the fiber strength and render impracticability of the sensor in practical applications.

On contrary, the LPG-based hydrogen sensor has relatively high sensitivity and need not damage the fiber coating. However, the proposed sensor can only be the transmission type, which is inconvenient for remote sensing. Besides, the multi-interferences between core mode and different cladding modes make the transmission spectrum of LPG very complicated, making it difficult to 
demodulate the spectrum signal.

\subsection{Interferometer-based hydrogen sensor}

The working principle of interferometer is that the two lights with same frequency, constant phase difference, and same transmission direction will interfere with each other at the meeting point. Interferometer-based hydrogen sensor relies on the assumption that the hydrogen interaction of sensitive film induces the stress and/or temperature change of interferometer device, which will change the effective phase difference of two lights, and then lead to the shift of interference spectrum. According to the structural style, the interferometer that used for hydrogen sensing can be classified into Mach-Zehnder interferometer (MZI), Fabry-Perot interferometer (FPI), and Sagnac interferometer.

\subsubsection{MZI-based sensor}

In general, a MZI is composed of two arms having different optical path lengths. When two beams, which propagate through two different optical paths, meet at a point, they will interfere with each other. The light emitted from light source will be divided firstly, then the two light beams couple and interfere with each other, and finally the interference intensity will be detected by a detector. The interference intensity can be expressed by [53]:

$$
I=I_{1}+I_{2}+2 \sqrt{I_{1} I_{2}} \cos \varphi
$$

where $I_{1}$ and $I_{2}$ are the intensities along the two optical paths; $\varphi$ is the phase difference between two optical paths, and can be defined as:

$$
\varphi=2 \pi\left|n_{\text {eff1 }} \mathrm{L}_{1}-n_{\text {eff }} \mathrm{L}_{2}\right| / \lambda+\varphi_{0}
$$

where $n_{\text {eff1 }}$ and $n_{\text {eff2 }}$ are the refractive indexes of two optical paths, $L_{1}$ and $L_{2}$ are the transmission length of two optical paths, and $\varphi_{0}$ is the initial interference phase. 
By coating sensitive film onto the MZI, the volume expansion of Pd-based sensitive film or exothermic reaction of $\mathrm{WO}_{3}$-based sensitive film in the presence of hydrogen will induce strain or temperature variation in the underlying MZI, which will then change the phase difference between two optical paths, and finally cause the resonant wavelength shift of the MZI. Therefore, the hydrogen concentration can be deduced by measuring the wavelength shift of MZI, in which the critical point of MZI is to effectively divide light and couple lights.

In 2010, Y. H. Kim et al. [54] proposed a MZI-based hydrogen sensor in one conventional SMF, as shown in Fig. 13. The fiber interferometer is fabricated by modifying the core structure of the fiber at two points along its length with electric arc discharge technology. For the case of the proposed MZI $\underline{\text { structure, }}$, the physical lengths of two arms are exactly the same: one is the core of the fiber and the other is the cladding part of the same fiber. However, there exists a constant phase difference between the two light beams, due to the slight refractive index difference between the core and the cladding modes. By coating the cladding surface of the fiber with $100 \mathrm{~nm}$ thickness Pd, the hydrogen sensor can be achieved. When Pd coating responds to hydrogen, the refractive index of Pd will change and then the spectral movement of the interferometer will be achieved in the wavelength domain. With the core modification separation of $40 \mathrm{~mm}$, the spectral shift of $0.4 \mathrm{~nm}$ is achieved for $\underline{4 \%}$ hydrogen concentration.

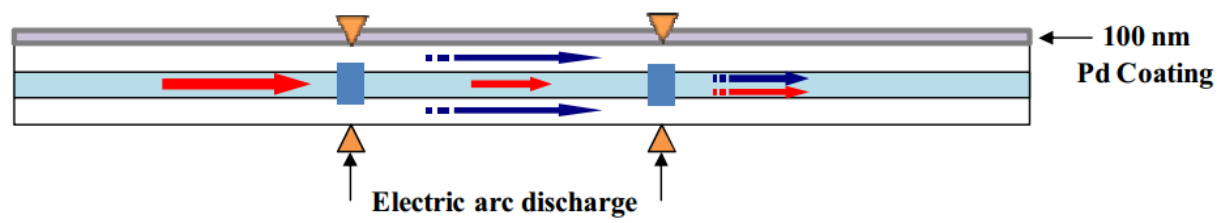

Fig. 13 Schematic probe structure of MZI-based hydrogen sensor in a single piece of conventional SMF with electric arc discharge

Then in 2012, M. Wang et al. [55] proposed a femtosecond laser fabricated fiber inline micro MZI with deposited Pd film for hydrogen sensing. By removing the fiber cladding and part of the fiber 
core, an open air-cavity is created which essentially formed a fiber in-line MZI as shown in Fig. 14(a). At the air-cavity head, the light beam is divided into toe beams: one light beam remains propagate in the fiber core while the other travels through the air-cavity, and both the light beams are recombined at the air-cavity end. Thus the interference will take place due to the phase difference induced by the effective refractive index difference between the fiber core and the air-cavity. For $100 \mathrm{~nm}$ thickness $P d$ film and $40 \mu \mathrm{m}$ micro cavity length, the proposed sensor shows a sensitivity of $\sim 0.155 \mathrm{~nm} \%$. However, it should be mentioned that the side cavity surface made by femtosecond laser cannot be smooth enough but coarse and irregular, and that it is not easy to remove the particles as small as $1 \mu \mathrm{m}$ in diameter. Furthermore, the temperature and humidity also affect the performances of the MZI coated with Pd film.

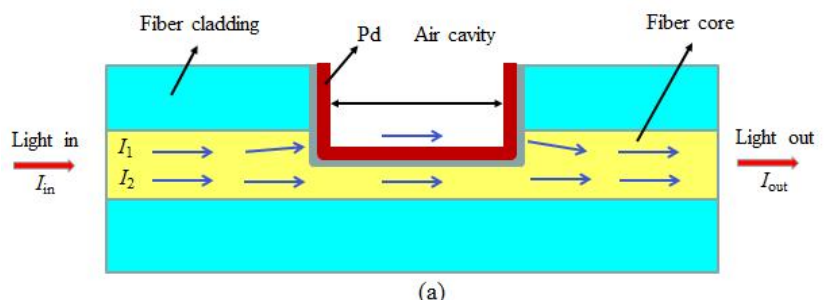

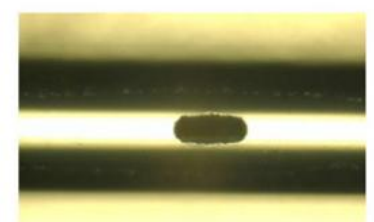

(b)

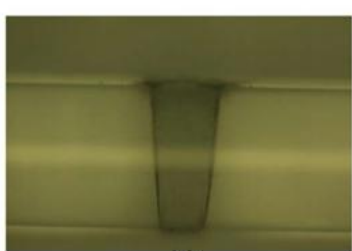

(c)

Fig. 14 Schematic probe structure of optical fiber hydrogen sensor based on a femtosecond laser fabricated fiber inline micro MZI

Both the hydrogen concentration variation and temperature change can result in wavelength shift of transmission spectrum in MZI, due to the induced optical path difference change. To resolve the temperature cross-sensitivity problem, the authors in 2014 improved this MZI by combining a FBG as shown in Fig. 15, which can simultaneously measure hydrogen concentration and temperature [56]. The responses of MZI coated with $40 \mathrm{~nm}$ thickness Pd and FBG to the hydrogen are measured. 
It is shown that the FBG's response will not affect by the change in hydrogen concentration, while an increase of hydrogen concentration will lead to a red shift of MZI's wavelength and the obtained sensitivity is $\sim 70 \mathrm{pm} / \%$. When the hydrogen concentration is changed from 0 to $8 \%$ with a step of $1 \%$ while the temperature is varied from 23 to $63{ }^{\circ} \mathrm{C}$, the wavelength shifts of MZI and FBG are measured to be $720 \mathrm{pm}$ and $140 \mathrm{pm}$, respectively. Assuming that the OSA resolution is $10 \mathrm{pm}$, the hydrogen concentration and temperature resolution can be estimated to be around $0.14 \%$ and $1{ }^{\circ} \mathrm{C}$.

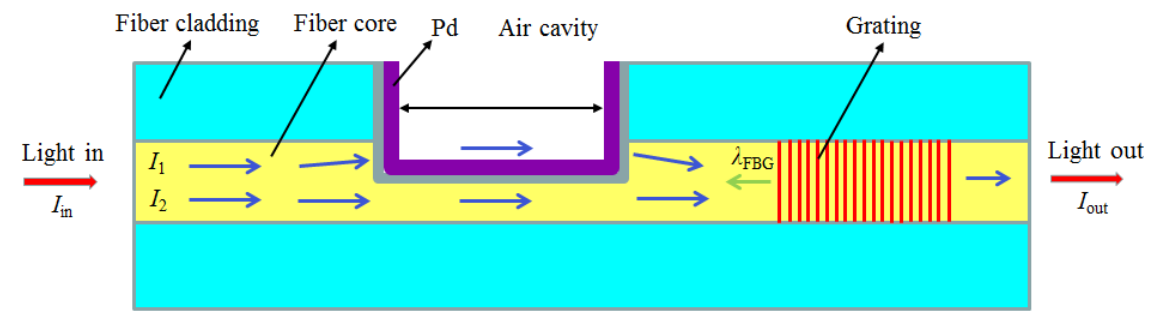

Fig. 15 Schematic probe structure of optical fiber hydrogen sensor based on a femtosecond laser fabricated fiber inline micro MZI and FBG for temperature compensation

Besides these, many modified MZIs have been proposed and utilized for hydrogen sensing. In 2014, F. Zhou et al. [57] proposed an all-fiber MZI based on photonic crystal fiber (PCF). One end-face of the PCF and part of the outer-face of the fiber are plated with a thin Pd film by magnetron sputtering, while the other end of the PCF is connected to the optical path, as shown in Fig. 16(a). The interference between core mode and cladding modes results in a MZI configuration, which is sensitive to the refractive index variation of sensitive film that coated on PCF. As shown in Fig. 16(b), the maximum wavelength shift of over $1.2 \mathrm{~nm}$ is obtained when hydrogen concentration changes from 0 to $5 \%$.

At the same time, T. Y. Hu et al. [58] demonstrated a miniaturized fiber device based on fiber inner air-cavity with periodical microstructures and platinum $(\mathrm{Pt})$-doped $\mathrm{WO}_{3}$ coating for hydrogen concentration sensing. As shown in Fig. 17(a), the fiber inner air-cavity is formed by using 
femtosecond laser micromachining together with fusion splicing technique and the line shape microstructures are inscribed by femtosecond laser beam scanning. Experimental results shown in Fig. 17(b) demonstrate that a maximum wavelength shift of $\sim 2.64 \mathrm{~nm}$ can be obtained when the hydrogen concentration is increased from $0 \%$ to $4 \%$ in volume percentage.

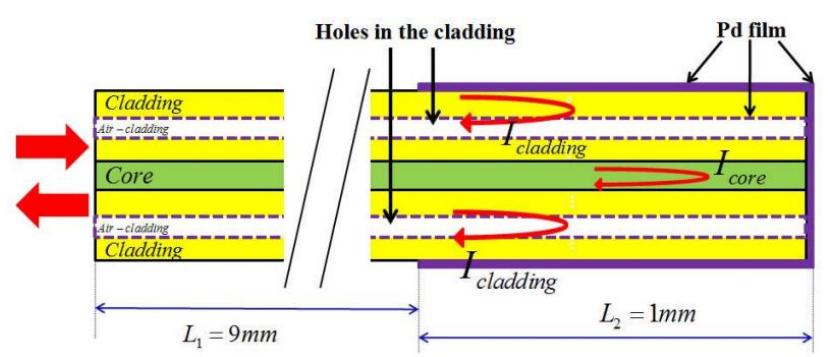

(a) Probe structure

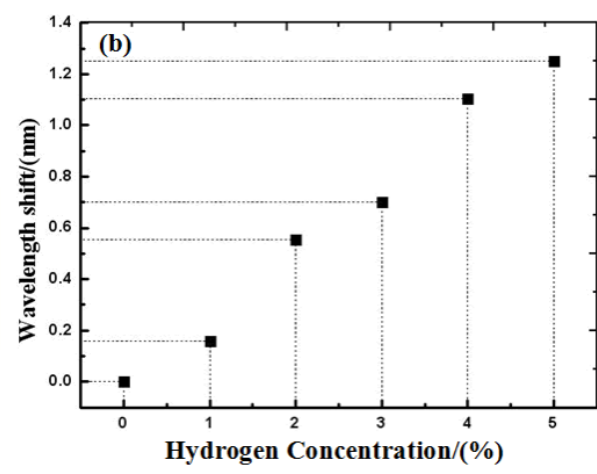

(b) Output response

Fig. 16 Schematic probe structure and response of optical fiber hydrogen sensor based on MZI constructed of PCF

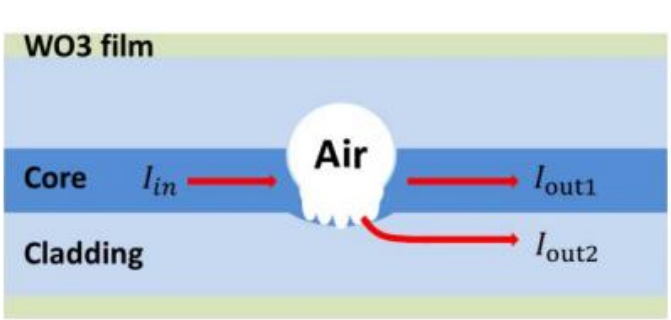

(a) Probe structure

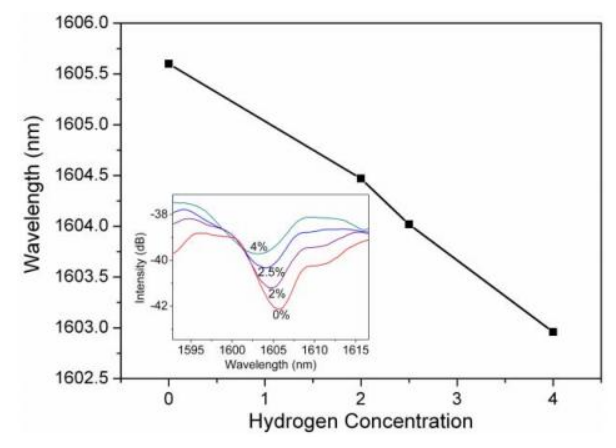

(b) Output response

Fig. 17 Schematic probe structure and response of optical fiber hydrogen sensor based on MZI constructed of fiber inner air-cavity with periodical microstructures

While in 2015, F. Gu et al. [59] proposed a hybrid photon-plasmon MZI by integrating single-crystal PdAu alloy nanowires with silica optical microfibers, as shown in Fig. 18(a). For the hybrid MZI, the lengths of sensing arm and reference arm are $2037 \mu \mathrm{m}$ and $1995 \mu \mathrm{m}$, respectively. To construct the sensing arm, two silica microfibers (drawn from standard silica optical fiber) are reversely placed on the $\mathrm{MgF}_{2}$ substrates with their tips protruding out of the substrate. The distance 
between the two tips $\underline{\text { is around }} 15 \mu \mathrm{m} . \mathrm{A} \mathrm{Pd}_{0.51} \mathrm{Au}_{0.49}$ nanowire with diameter of $210 \mathrm{~nm}$ and sensing length of $17 \mu \mathrm{m}$ is placed across the tips via micromanipulation. To construct the reference arm, another microfiber is placed close to the sensing arm by an evanescent wave coupling technique.

Two couplers formed between the silica microfibers are maintained on the substrate by van der Waals force and electrostatic force. As shown in Fig. 18(b), the dip wavelength of the interference fringe shifts about $3.5 \mathrm{~nm}$ when hydrogen concentration is increased from 0 to $20 \%$.

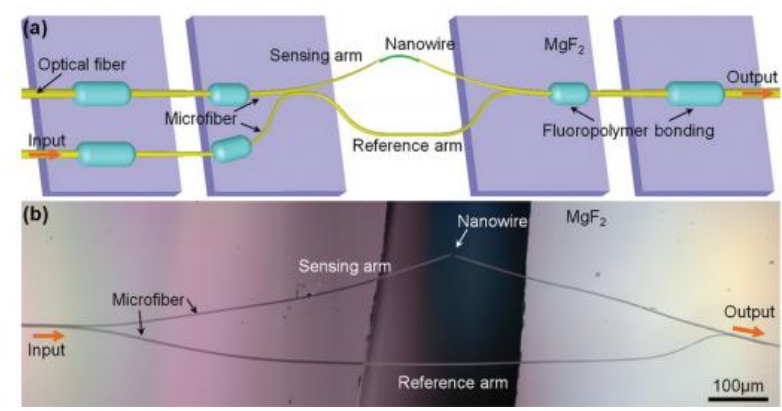

(a) Sensor structure
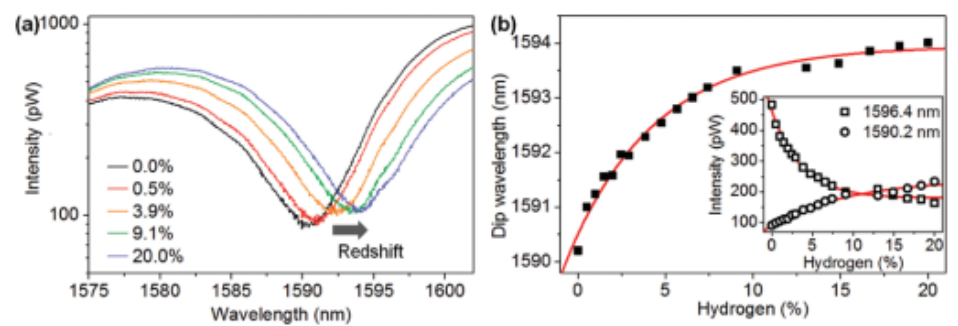

(b) Output response

Fig. 18 Schematic structure and response of optical fiber hydrogen sensor based on hybrid photon-plasmon MZI

Then in 2016, Z. P. Yu et al. [60] reported a fiber taper interferometric hydrogen sensor. The tapering process is carried out with a commercial fusion splicer by precisely controlling the pulling and feeding velocity, as well as arc strength. The taper can naturally act as a MZI and intrinsically offer a transmission spectrum with periodic interference fringes. Experimental results demonstrate that the sensor with a waist diameter of $3 \mu \mathrm{m}$ and Pd film thickness of $4 \mathrm{~nm} \underline{\text { can }}$ present a spectral shift up to $-1.99 \mathrm{~nm}$ for hydrogen concentration of $5 \%$, as a result of strong evanescent field interaction with the Pd overlay. Besides, the authors fabricate a number of sensors with identical 
parameters and find that the relative error ratio in waist diameter is less than $6 \%$ and that in hydrogen response is $4.2 \%$, showing good reproducibility and high precision.

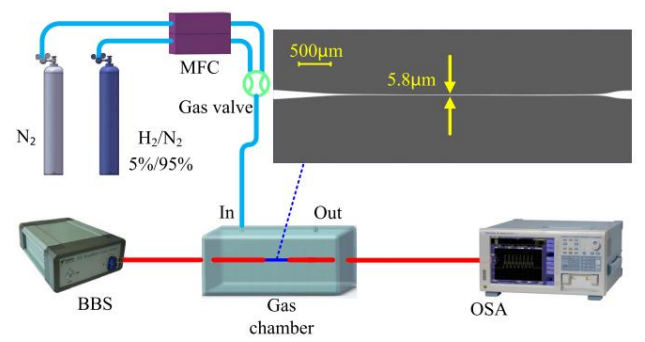

(a) Sensor structure
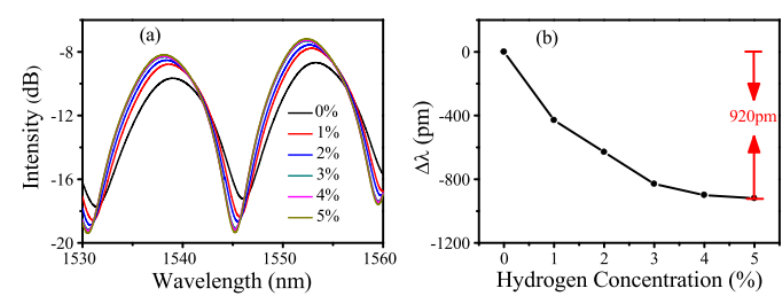

(b) Output response

Fig. 19 Schematic structure and response of optical fiber hydrogen sensor based on tapered MZI

\subsubsection{FPI-based sensor}

FPI can be mainly classified as intrinsic Fabry-Perot interferometer (FPI) and extrinsic Fabry-Perot interferometer (EFPI). The optical fiber FPI can be approximately equivalent to the two beam interferometer. Compared to MZI, the FPI works as a reflective device. The reflective optical intensity can also be expressed as:

$$
I=I_{1}+I_{2}+2 \sqrt{I_{1} I_{2}} \cos \varphi
$$

which is similar to Eq. (7), but the $I_{1}$ and $I_{2}$ are intensities of the two reflective beams, respectively, and $\varphi=4 \pi n_{\text {eff }} L / \lambda$ is the phase difference of the two reflective beams. Similarly to MZI, the hydrogen concentration can be detected by monitoring the wavelength shift of reflective resonant spectrum, which is caused by the interaction between sensitive film and hydrogen.

In 2013, M. Wang et al. [61] proposed a modified EFPI hydrogen sensor, in which the FPI cavity is fabricated by femtosecond laser micromachining near the fiber end and deposited with Pd film, as shown in Fig. 20(a). For the FPI with $L_{1}=20 \mu \mathrm{m}, L_{2}=50 \mu \mathrm{m}$ and $n_{\text {film }}=20 \mu \mathrm{m}$, the shifts of the interferometer output spectrum are $10 \mathrm{pm}, 30 \mathrm{pm}, 100 \mathrm{pm}$, and $150 \mathrm{pm}$, respectively, corresponding to the hydrogen concentration of $2 \%, 4 \%, 6 \%$, and $8 \%$ (see Fig. 20(b)). The proposed sensor is 
compact, easy in fabrication, and has high potential for hydrogen detection.
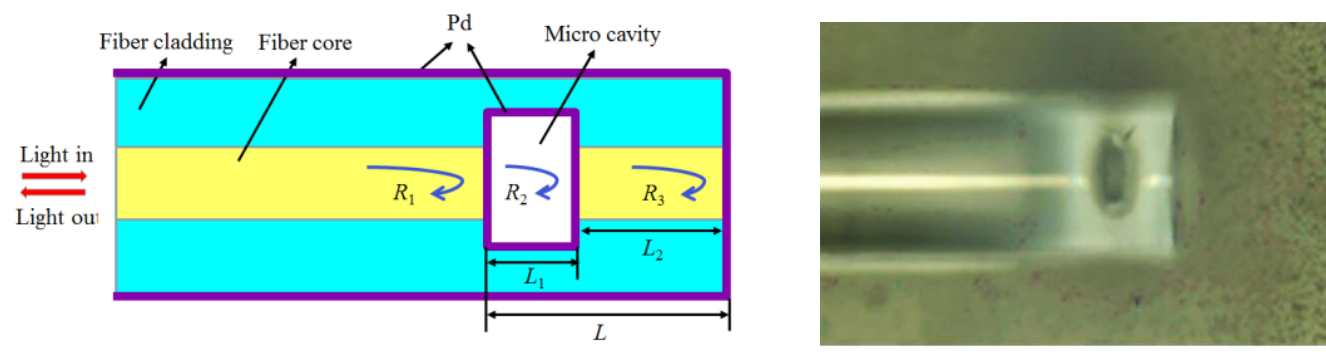

(a) Probe structure
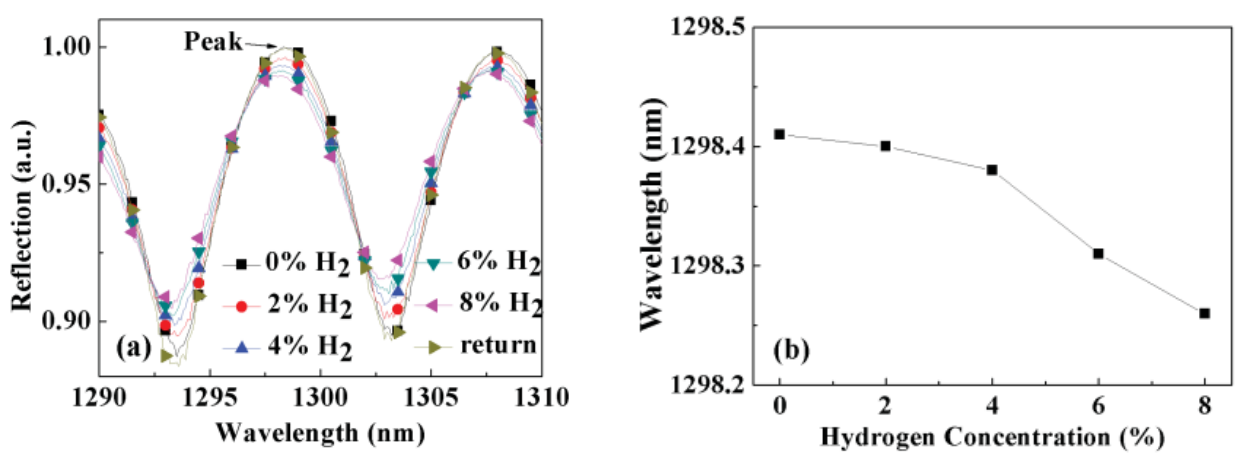

(b) Output response

Fig. 20 Schematic probe structure and response of optical fiber hydrogen sensor based on FPI fabricated by femtosecond laser micromachining

Latter in 2015, Y. Wang et al. [62] proposed another EFPI-based hydrogen sensor. As shown in

Fig. 21, the air cavity of FPI is formed by inserting two SMFs into a partially polymer-filled glass

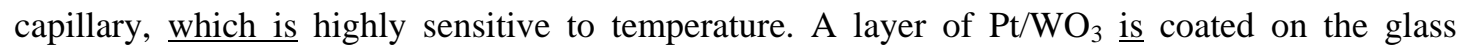
capillary of the FPI and served as a reaction heater upon hydrogen exposure. The heat locally raises the FPI temperature, and then leads to the wavelength shift of interference spectrum. The average wavelength shift of sensor's interference dip is $-20.3 \mathrm{~nm}$ upon exposure to $2 \%$ hydrogen concentration.

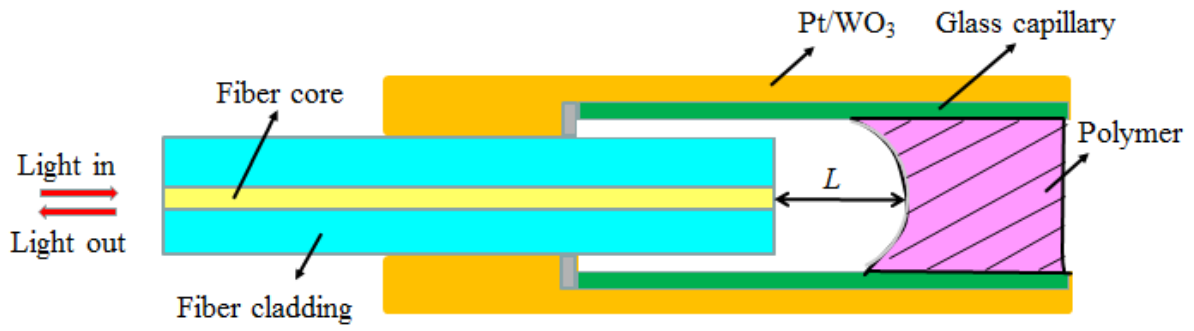

(a) Probe structure 

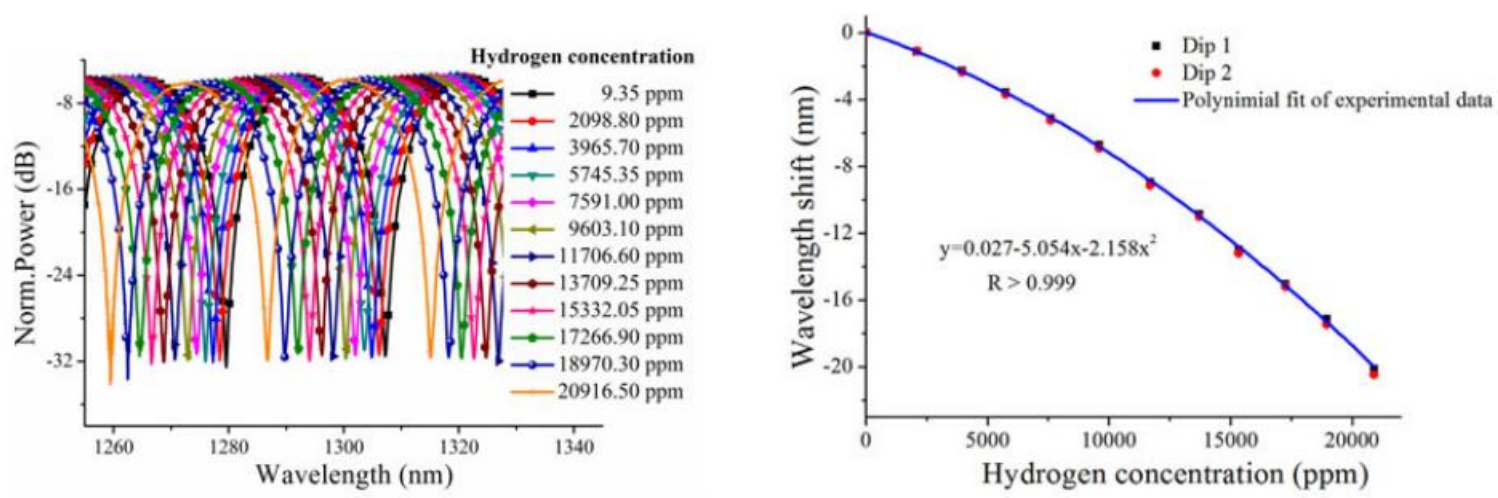

(a) Output response

Fig. 21 Schematic probe structure and response of optical fiber hydrogen sensor based on FPI formed by inserting two SMFs into a partially polymer-filled glass capillary

In the same year, Y. U. Caibin et al. [63] proposed an IFPI hydrogen sensor. As shown in Fig. 22, the sensor consists of a MMF FP structure and a Pd-Y film coated at the fiber end. There are three reflective interfaces in this sensor, including the SMF end, the air-gap, and the MMF end, respectively. When exposed to hydrogen, the refractive index variation of Pd-Y film will change the fringe contrast of the reflective FPI spectrum. Meanwhile, the temperature can be measured according to the wavelength shift of the spectrum. Experimental results demonstrate that the maximum fringe contrast of $0.5 \mathrm{~dB}$ is obtained when the hydrogen concentration is changed from $0 \%$ to $5.5 \%$.

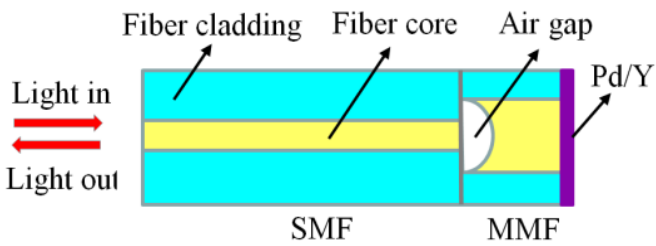

Fig. 22 Schematic probe structure of optical fiber hydrogen sensor based on FPI consisted of MMF

\subsubsection{Sagnac-based sensor}

The Sagnac interferometer, also known as fiber loop mirror based on a ring configuration, is one of the important devices in communications, filters, and sensors. Normally, a section of birefringent fiber is inserted in the loop and can induce optical path difference of the two counter-propagating 
waves and cause an interference spectrum. The output interference transmission of the Sagnac interferometer can be described as:

$$
I=[1-\cos (2 \pi B L / \lambda)] / 2
$$

where $B$ is the refractive index difference between the fast axis and the slow axis of the birefringent fiber, $L$ is the length of birefringent fiber, and $\lambda$ is the wavelength of light beam in free space. When the phase difference of the panda fiber satisfies the condition of $2 \pi B L \lambda_{\text {Dip }}=2 k \pi$, where $k$ is an integer, a resonance dip will appear in the transmission spectrum of the Sagnac interferometer, which can be written as: $\lambda_{\text {Dip }}=B L k$. Similarly, the $B$ and $L$ of birefringent fiber coated with hydrogen sensitive film will change with the hydrogen concentration variation. Therefore, the hydrogen concentration can be deduced by measuring the wavelength shift of Sagnac interferometer coated with sensitive film.

In this case, Y. Kim et al. [64] demonstrated an optical fiber Sagnac interferometer hydrogen sensor as shown in Fig. 23(a), in which the interferometer is composed of a polarization beam splitter (PBS), two quarter-wave plates, and a polarization-maintaining fiber coated with Pd whose thickness $\underline{\text { is }} \sim 400 \mathrm{~nm}$ (see Fig. 23(b)). As the two orthogonally-polarized light components split from the PBS undergo the birefringence of the PMF, an interference spectrum will form when they are combined at the PBS. For hydrogen concentration of 4\%, one dip in the output interference spectrum shows a wavelength shift of $\sim 2.48 \mathrm{~nm}$ (see Fig. 23(c)). The response time of the proposed sensor is $10 \mathrm{~s}-12.5 \mathrm{~s}$. 


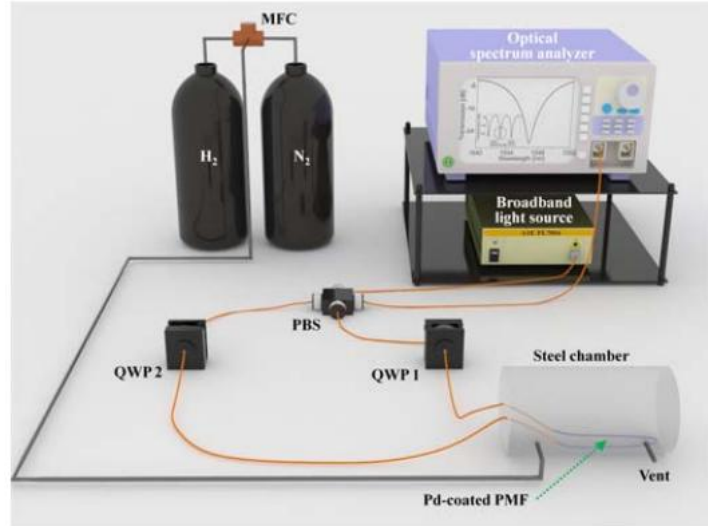

(a) Sensor structure

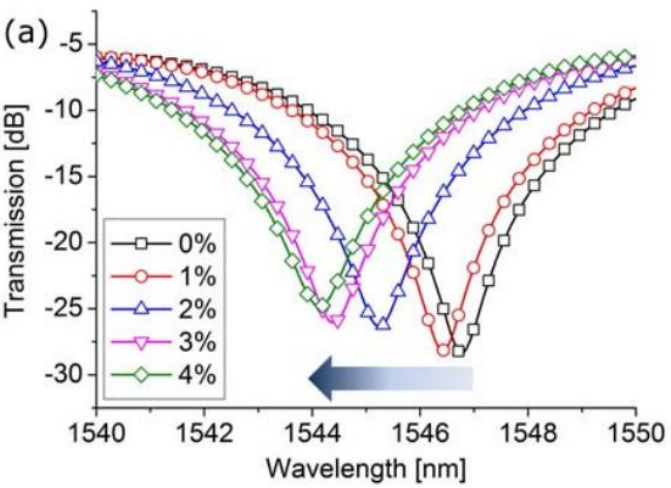

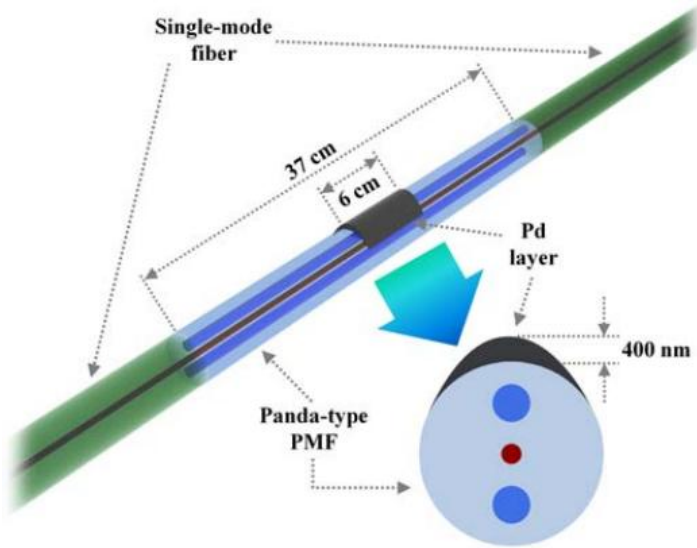

(b) Probe structure

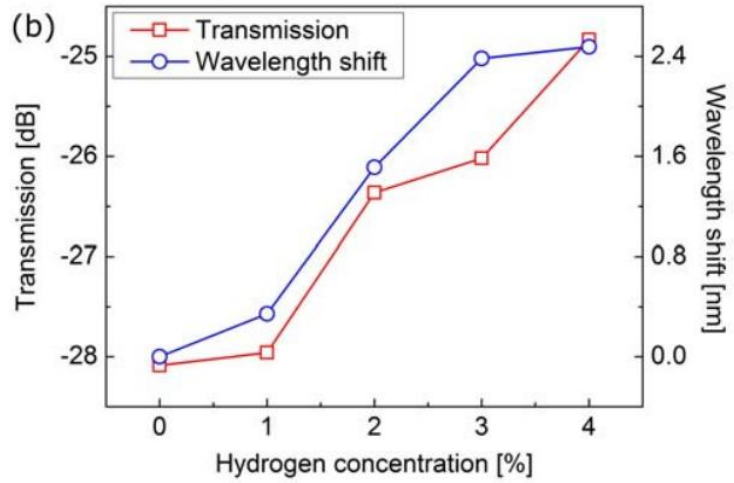

(c) Output response

Fig. 23 Schematic sensor structure and response of optical fiber hydrogen sensor based on Sagnac interferometer

Then in 2015, Y. Yang et al. [65] demonstrated another optical fiber Sagnac interferometer hydrogen sensor based on a polarization-maintaining photonic crystal fiber (PM-PCF). As shown in

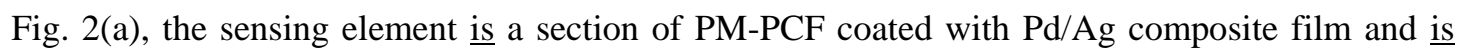
incorporated into a SMF Sagnac loop interferometer. For Pd/Ag composite film with $\sim 100 \mathrm{~mm}$ long $\underline{\text { and atomic ratio of } 91: 9}$, the dip wavelength will shift $\sim 1.310 \mathrm{~nm}$ when hydrogen concentration $\underline{\text { is }}$ varied from 0 to $1 \%$, with sensitivity coefficient of about $131 \mathrm{pm} \%$ within $1 \%-4 \%$ hydrogen

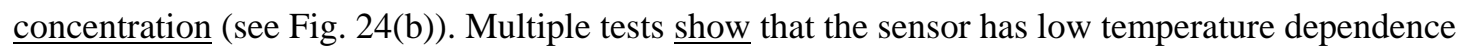
and good repeatability. 


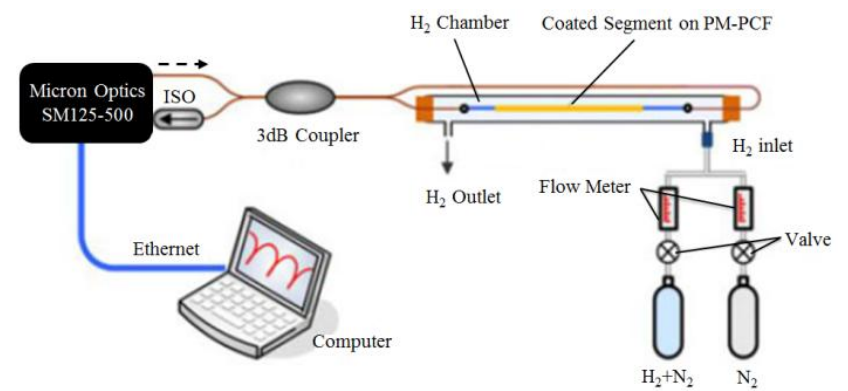

(a) Sensor structure

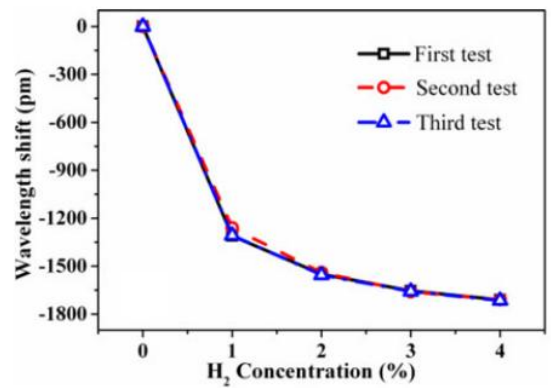

(b) Output response

Fig. 24 Schematic sensor structure and response of optical fiber hydrogen sensor based on Sagnac interferometer consisted of polarization-maintaining PCF

Recently in 2016, B. Xu et al. [66] proposed and demonstrated an optical fiber Sagnac interferometer hydrogen sensor based on panda fiber with Pt-loaded $\mathrm{WO}_{3} / \mathrm{SiO}_{2}$ coating. When $\mathrm{Pt} / \mathrm{WO}_{3}$ film is exposed to hydrogen, the exothermic reaction will raise the temperature of the panda fiber, resulting in the resonant wavelength shift of the interferometer, and the resonant dip obtained has a large extinction ratio of $25 \mathrm{~dB}$ and a narrow linewidth of $2.5 \mathrm{~nm}$. Such a device responds fast to hydrogen, exhibits a high sensitivity of $-7.877 \mathrm{~nm} / \%$ within the range of $0 \%-1.0 \%$ and is robust, low cost, and easy to fabricate.

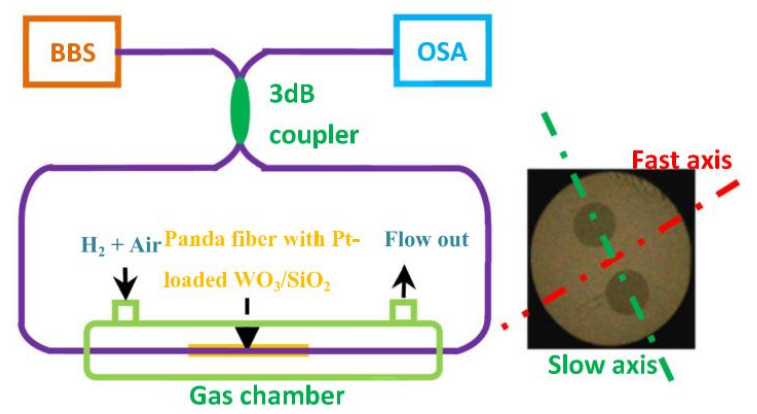

(a) Sensor structure

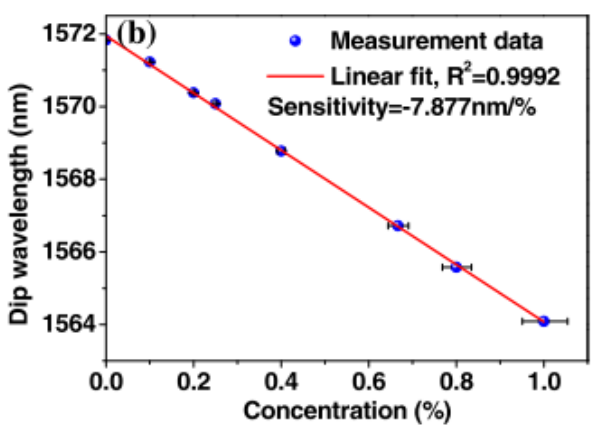

(b) Output response

Fig. 25 Schematic sensor structure and response of optical fiber hydrogen sensor based on Sagnac interferometer consisted of panda fiber

\subsubsection{Advantages and disadvantages}

The sensing performances and structures of various types of interferometer-based optical fiber

hydrogen sensors mentioned above are presented in Table 3. 
Table 3. Performances comparison of interferometer-based optical fiber hydrogen sensors

\begin{tabular}{|c|c|c|c|c|c|c|}
\hline $\begin{array}{l}\text { Sensing } \\
\text { mechanism }\end{array}$ & Sensing structure & $\begin{array}{l}\text { Sensitive film } \\
\text { (Thickness) }\end{array}$ & $\begin{array}{l}\text { Concentra } \\
\text { tion range }\end{array}$ & Sensitivity & $\begin{array}{l}\text { Response } \\
\text { time }\end{array}$ & Ref. \\
\hline \multirow{7}{*}{ MZI } & $\begin{array}{l}\text { SMF with two points of } \\
\text { modified core structure }\end{array}$ & $\operatorname{Pd}(100 \mathrm{~nm})$ & $4 \%$ & $0.1 \mathrm{~nm} / \%$ & $10 \mathrm{~min}$ & {$[54]$} \\
\hline & $\begin{array}{l}\text { Air cavity with removed } \\
\text { SMF cladding and part of } \\
\text { fiber core }\end{array}$ & $\operatorname{Pd}(100 \mathrm{~nm})$ & & $0.155 \mathrm{~nm} / \%$ & & {$[55]$} \\
\hline & $\begin{array}{l}\text { Inline air cavity MZI and } \\
\text { FBG }\end{array}$ & $\mathrm{Pd}(40 \mathrm{~nm})$ & $0-8 \%$ & $0.07 \mathrm{~nm} / \%$ & -- & {$[56]$} \\
\hline & $\begin{array}{l}\text { One end-face of PCF and } \\
\text { part of outer-face of PCF }\end{array}$ & $\mathrm{Pd}(50 \mathrm{~nm})$ & $0-5 \%$ & $0.24 \mathrm{~nm} / \%$ & $15 \mathrm{~s}$ & {$[57]$} \\
\hline & $\begin{array}{l}\text { Fiber inner air-cavity with } \\
\text { periodical micro structures }\end{array}$ & $\mathrm{Pt} / \mathrm{WO}_{3}$ & $0-4 \%$ & $0.66 \mathrm{~nm} / \%$ & $2 \min$ & [58] \\
\hline & $\begin{array}{l}\text { Two silica optical } \\
\text { microfibers }\end{array}$ & $\begin{array}{l}\mathrm{PdAu} \text { alloy } \\
\text { nanowire }\end{array}$ & $0-20 \%$ & $0.175 \mathrm{~nm} / \%$ & -- & [59] \\
\hline & Tapered SMF & $\mathrm{Pd}(4 \mathrm{~nm})$ & $5 \%$ & $0.4 \mathrm{~nm} / \%$ & $30 \mathrm{~s}$ & {$[60]$} \\
\hline \multirow{3}{*}{ FPI } & $\begin{array}{l}\text { Femtosecond laser } \\
\text { micromached air cavity }\end{array}$ & $\mathrm{Pd}(20 \mathrm{~nm})$ & $0-8 \%$ & $18.75 \mathrm{~nm} / \%$ & $2 \min$ & [61] \\
\hline & $\begin{array}{l}\text { Two SMFs inserted into a } \\
\text { partially polymer-filled } \\
\text { glass capillary }\end{array}$ & $\mathrm{Pt} / \mathrm{WO}_{3}$ & $2 \%$ & $10 \mathrm{~nm} / \%$ & $<1 \min$ & {$[62]$} \\
\hline & SMF-air gap-MMF & $\mathrm{Pd} / \mathrm{Y}$ & $0-5.5 \%$ & $0.09 \mathrm{~dB} / \%$ & -- & {$[63]$} \\
\hline \multirow{3}{*}{ Sagnac } & $\begin{array}{l}\text { Polarization-maintaining } \\
\text { fiber }\end{array}$ & $\operatorname{Pd}(400 \mathrm{~nm})$ & $4 \%$ & $0.62 \mathrm{~nm} / \%$ & $10 \mathrm{~s}-12.5 \mathrm{~s}$ & {$[64]$} \\
\hline & $\begin{array}{l}\text { Polarization-maintaining } \\
\text { PCF }\end{array}$ & $\begin{array}{l}\mathrm{Pd} / \mathrm{Ag} \\
\mathrm{nm})\end{array}$ & $1 \%-4 \%$ & $0.131 \mathrm{~nm} / \%$ & -- & {$[65]$} \\
\hline & Panda fiber & $\mathrm{Pt} / \mathrm{WO}_{3}\left(\mathrm{SiO}_{2}\right)$ & $0-1 \%$ & $7.877 \mathrm{~nm} / \%$ & $1 \mathrm{~min}$ & {$[66]$} \\
\hline
\end{tabular}

Compared with other hydrogen sensors based on evanescent field or FBG, the interferometer-based hydrogen sensor possesses more flexible and simple structure, which is easy to fabricate and much more durable because that the physical or chemical etching/polishing/tapering process is not necessary for the optical fiber, and thus is highly resistant to external stress applied on a transverse axis of an optical fiber. However, the demodulation of interference spectrum is difficult and needs expensive optical spectrum analyzer. Besides, the measurement range is limited due to the periodic output signal.

Especially, for MZI-based hydrogen sensor, if multiple modes are existed and interfered with each other, the interference spectrum will be very disorder, and thus the resonant peak will difficult 
to search; for FPI-based hydrogen sensor, it still suffers some drawbacks in practical applications, such as: restriction on cavity size owing to coupling loss, offsets of fiber end faces, and large transmission loss; while for Sagnac-based hydrogen sensor, the long fiber line will bring many external interfering agents, such as vibration and temperature, on the sensing system, and finally results in measurement errors.

\subsection{Surface plasmon resonance-based hydrogen sensor}

Surface plasmons are the collective oscillations of electrons in metal stimulated by the transverse magnetic (TM) polarized light. Resonance takes place when the propagation constant of the excitation light is exactly match with the propagation constant of the surface plasmon wave, which causes the transfer of energy from incident wave to surface plasmon wave. Therefore, the intensity carried with the reflected light from the surface drops to the minimum possible value. For a given metal, the resonance condition is highly sensitive to the dielectric constant of the medium in contact with the metal, the angle of incidence, and the wavelength of the excitation light. When the angle of incidence is fixed, the resonance occurs at a particular wavelength called the resonant wavelength. When the dielectric constant of the dielectric medium changes, the value of the resonance parameter changes. In other words, the position of the dip in the surface plasmon resonance (SPR) spectrum changes as the refractive index of the dielectric medium in contact with the metal changes [67]. Generally, the metals of gold, silver, and copper are used for supporting surface plasmons. From the above analyses, it is easy to think that the hydrogen concentration can be measured by monitoring the shift of resonance spectrum if the sensitive film is properly coated onto the surface of metal.

In 2012, Bevenot et al. [68] presented a SPR multimode optical fiber hydrogen sensor based on intensity modulation. The sensor consists of a Pd layer deposited on a section of the fiber core, after 
removing the optical cladding. The variation in $\underline{\mathrm{Pd} \text { complex dielectric constant during the hydrogen }}$ loading causes a modification of the SPR and then results in a decrease of the loss of the guided light at the Pd reflection interface. The hydrogen concentration can be obtained by measuring the change in transmitted intensity when the fiber is illuminated by a laser diode with a fixed incidence angle. Finally, measurement of hydrogen concentration as low as $0.8 \%$ is demonstrated to be possible. Nevertheless, the power distribution mode of light in the fiber is very sensitive to mechanical disturbances and fiber impurities.

Latter in 2011, C. Perrotton et al. [69] have numerically demonstrated the first SPR fiber hydrogen sensor based on spectral modulation. As shown in Fig. 26, a transducer layer, which is a multilayer stack made of a silver, a silica and a Pd layer, is deposited on the outside of a MMF, after removing the optical cladding. The silica thickness tunes the resonant wavelength, whereas the $\underline{\text { thicknesses of silver and Pd determines }}$ the sensor sensitivity. In an optimal configuration (NA=0.22, core radius $=100 \mu \mathrm{m}$ and transducer length $=1 \mathrm{~cm}$ ), the resonant wavelength is shifted over $17.6 \mathrm{~nm}$ for hydrogen concentration of $4 \%$, in the case of the $35 \mathrm{~nm} \mathrm{Ag} / 100 \mathrm{~nm} \mathrm{SiO} / 23 \mathrm{~nm} \mathrm{Pd}$ multilayer.

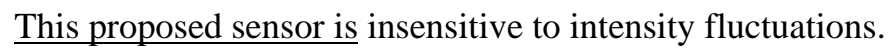

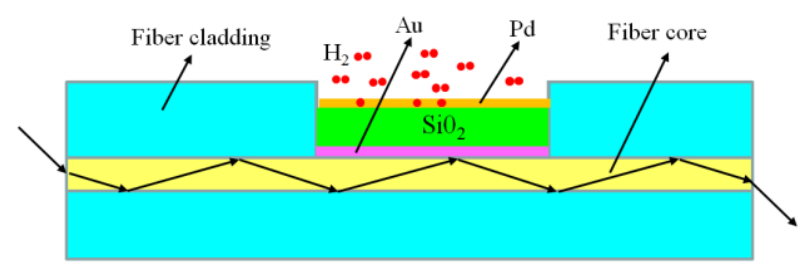

Fig. 26 Schematic probe structure of SPR hydrogen sensor formed with etched MMF

Then in 2013, the authors [70] presented the experimental response of this proposed sensor. The sensor consists of a multilayer of $35 \mathrm{~nm} \mathrm{Au} / 180 \mathrm{~nm} \mathrm{SiO}_{2} / \mathrm{Pd}$ deposited on a step-index MMF core. It is demonstrated that the sensitivity and selectivity of the sensor are optimal at a Pd thickness of $3.75 \mathrm{~nm}$. The sensor is sensitive to hydrogen concentration ranging between $0.5 \%$ and $4 \%$ hydrogen 
in argon, with a spectral shift of about $5 \mathrm{~nm}$ and response time less than $15 \mathrm{~s}$.

In the same year, X. Wang et al. [71] proposed a same optical fiber SPR hydrogen sensor, in which a MMF coated with $\mathrm{Pt} / \mathrm{WO}_{3}$ composite film is used as the sensing region. Theoretical results $\underline{\text { demonstrate that for the optimized structure (multilayer of } 35 \mathrm{~nm} \mathrm{Ag} / 100 \mathrm{~nm} \mathrm{SiO}} 2 / 180 \mathrm{~nm} \mathrm{WO} 3 / 3$ $\mathrm{nm} \mathrm{Pt}$ ), the resonant wavelength theoretically shifts $17.4 \mathrm{~nm}$ at a concentration of $2 \%$ hydrogen in argon.

Meanwhile, the authors [72] also demonstrated a dual-channel optical fiber hydrogen sensor by cascading two SPR sensors on one MMF. For the first channel, it consists of a multilayer of $40 \mathrm{~nm}$ $\mathrm{Ag} / 80 \mathrm{~nm} \mathrm{SiO}{ }_{2} / 160 \mathrm{~nm} \mathrm{WO} / 3 \mathrm{~nm} \mathrm{Pt}$ multilayer, while for the second channel, it consists of a

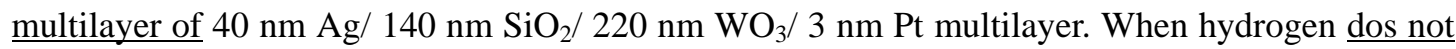
leak into the first channel while the hydrogen concentration in the second channel increases from 0 to $2 \%$, the resonant wavelength of the first channel remains almost unchanged, and the resonant wavelength of the second channel shifts $25 \mathrm{~nm}$ towards short wavelength. However, when hydrogen does not leak into the second channel while the hydrogen concentration in the first channel increases from 0 to $2 \%$, the resonant wavelength of the second channel remains almost unchanged, and the resonant wavelength of the first channel shifts $13 \mathrm{~nm}$ towards short wavelength. Furthermore, when the hydrogen concentration in both channels increase from 0 to $2 \%$, the two resonant wavelengths of the two channels shift $13 \mathrm{~nm}$ and $25 \mathrm{~nm}$ towards short wavelength, respectively. The results demonstrate that the two resonant wavelengths independently depend on the hydrogen concentrations in respective channels, and there is a one-to-one relationship between the resonant wavelength and hydrogen concentration for each channel. By measuring the resonant wavelength of each channel, the proposed sensor can achieve the simultaneous detection of hydrogen 
concentrations in two different areas.

Besides, A. Hosoki et al. [14] have also reported a SPR hydrogen sensor by means of hetero-core structured optical fibers with a multilayer of $\mathrm{Au} / \mathrm{Ta}_{2} \mathrm{O}_{5} / \mathrm{Pd}$, which can operate at the near infrared wavelength of $850 \mathrm{~nm}$. The optical fiber sample is fabricated with a 15-mm-long segment of a SMF inserted into a MMF. The SMF and MMF fibers have the same cladding diameter of $125 \mu \mathrm{m}$, but different core diameters of $3 \mu \mathrm{m}$ and $50 \mu \mathrm{m}$, respectively. Owing to the core diameter difference between SMF and MMF, most of the transmitted lights in the transmission line will largely leak into the cladding region of the SMF sensor element. Light in the cladding will generate evanescent wave

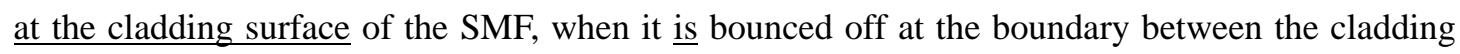
region and the surrounding medium under the condition of total internal reflection. At the other end of the SMF sensor element, some lights are re-coupled to the core of MMF. Therefore, SPR waves

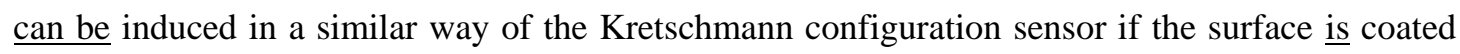

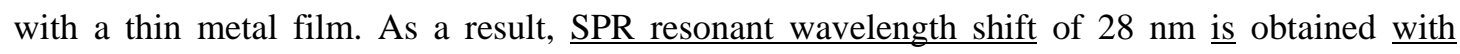
response time of $15 \mathrm{~s}$ at a concentration of $4 \%$ hydrogen in nitrogen for a multilayer of $25 \mathrm{~nm} \mathrm{Au} / 60$ $\underline{\mathrm{nm} \mathrm{Ta}} 2 \underline{\mathrm{O}_{5}} \underline{\underline{5 \mathrm{~nm} \mathrm{Pd}} .}$

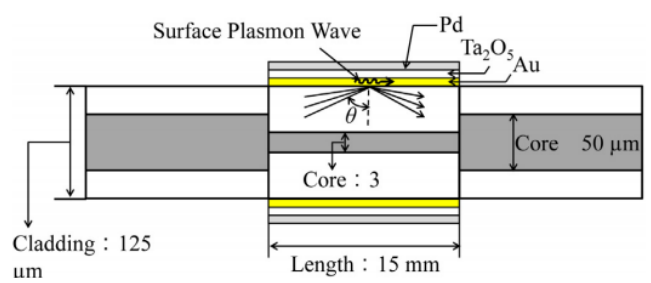

Fig. 27 Schematic probe structure of SPR hydrogen sensor formed with hetero-core structured optical fibers

Then in 2014, the authors [73] further investigated the hydrogen curing effect on the response time and sensitivity of this sensor, by changing the annealing temperature to be $400{ }^{\circ} \mathrm{C}, 600{ }^{\circ} \mathrm{C}$, and $\underline{800^{\circ} \mathrm{C}}$. When the $25 \mathrm{~nm} \mathrm{Au} / 60 \mathrm{~nm} \mathrm{Ta}{ }_{2} \mathrm{O}_{5} / 10 \mathrm{~nm} \mathrm{Pd}$ multilayer film annealed at $600{ }^{\circ} \mathrm{C}$ is cured with $4 \%$ hydrogen in nitrogen, it is found that a lot of nano-sized cracks are produced on the Pd 
surface. After hydrogen curing process, the response time is improved to be $8 \mathrm{~s}$ with sensor sensitivity remains unchanged.

In 2015, R. Tabassum et al. [74] proposed a theoretical model of SPR-based hydrogen sensor by utilizing Pd supported $\mathrm{ZnO}$ multilayer and their nanocomposite onto a step-index plastic-clad silica MMF. One of the two probes considered has multilayer of $\mathrm{ZnO}$ and Pd (see Fig. 28(a)) while the other one has a layer of their composite (see Fig. 28(b)) over an Ag coated fiber without cladding. For $80 \mathrm{~nm}$ thickness $\mathrm{ZnO}$ : Pd nanocomposite film and 55\% (volume percent) nanoparticles in host material, the proposed sensor shows a sensitivity of $34.75 \mathrm{~nm} / \%$, which is more than twofold of the sensing probe coated with multilayer of $\mathrm{ZnO}$ and $\mathrm{Pd}$.

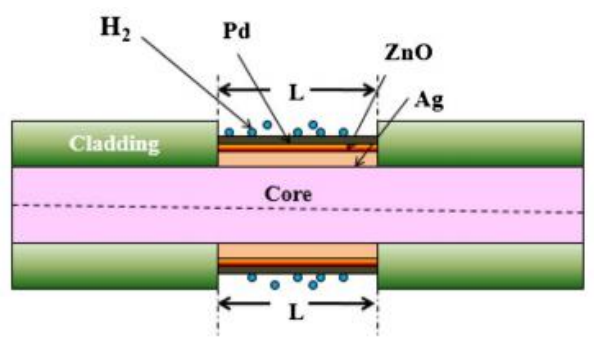

(a) Multilayers of $\mathrm{ZnO}$ and $\mathrm{Pd}$

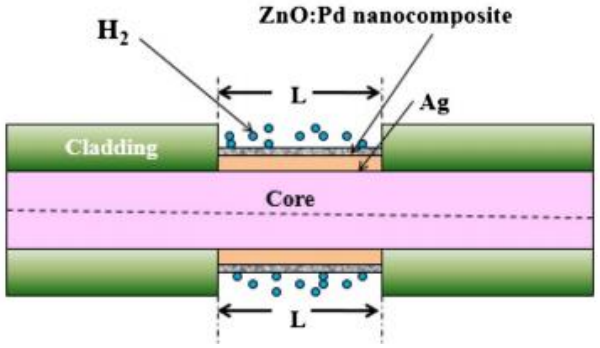

(b) Composite of $\mathrm{ZnO}: \mathrm{Pd}$

Fig. 28 Schematic probe structure of SPR hydrogen sensor formed with step-index plastic-clad silica MMF

Then in 2016, the authors [75] have further built an experimental system of SPR hydrogen sensor with Pd supported $\mathrm{ZnO}$ nanocomposite film (as shown in Fig. 29), to verify the above theoretical

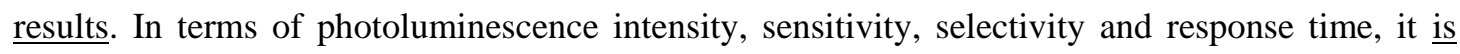
demonstrated that the probe with $\mathrm{ZnO}_{0.6} \mathrm{Pd}_{0.4}$ nanocomposite owns the best performances. For a concentration of $4 \%$ hydrogen in nitrogen, the resonant wavelength shifts about $80 \mathrm{~nm}$ with the response time and recovery time of around $1 \mathrm{~min}$. 


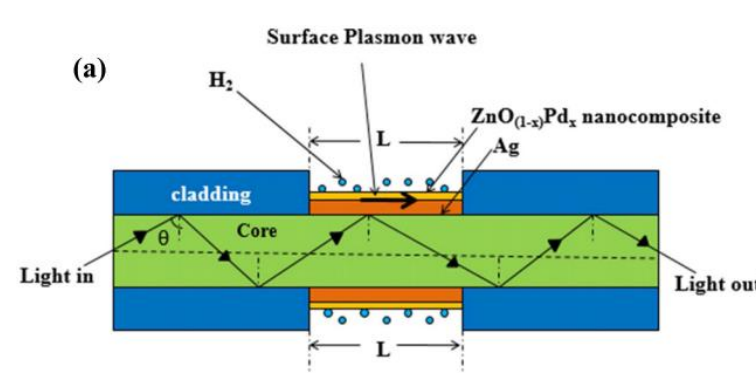

(a) Probe structure

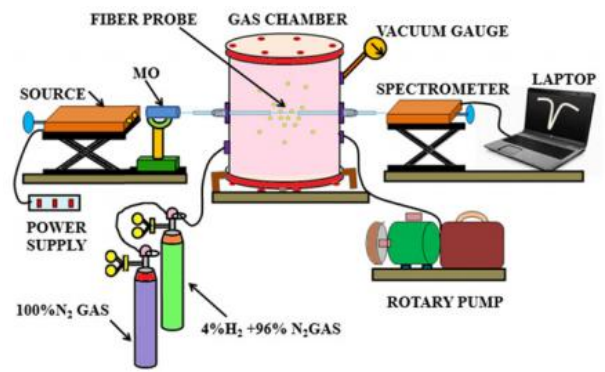

(b) Sensor structure

Fig. 29 Experimental structure of SPR hydrogen sensor with $\mathrm{ZnO}_{0.6} \mathrm{Pd}_{0.4}$ nanocomposite film

The sensing performances and structures of various types of SPR-based optical fiber hydrogen

sensors mentioned above are presented in Table 4.

Table 4. Performances comparison of SPR-based optical fiber hydrogen sensors

\begin{tabular}{|c|c|c|c|c|c|}
\hline Sensing structure & $\begin{array}{l}\text { Sensitive film } \\
\text { (Thickness) }\end{array}$ & $\begin{array}{l}\text { Concentration } \\
\text { range }\end{array}$ & Sensitivity & $\begin{array}{l}\text { Response } \\
\text { time }\end{array}$ & Ref \\
\hline Step-index MMF without cladding & $\begin{array}{l}35 \mathrm{~nm} \mathrm{Ag} / 100 \mathrm{~nm} \\
\mathrm{SiO}_{2} / 3 \mathrm{~nm} \mathrm{Pd}\end{array}$ & $4 \%$ & $4.4 \mathrm{~nm} / \%$ & -- & {$[69]$} \\
\hline Step-index MMF without cladding & $\begin{array}{l}35 \mathrm{~nm} \mathrm{Au} / 80 \mathrm{~nm} \\
\mathrm{SiO}_{2} / 3.75 \mathrm{~nm} \mathrm{Pd}\end{array}$ & $0.5 \%-4 \%$ & $1.43 \mathrm{~nm} / \%$ & $<15 \mathrm{~s}$ & {$[70]$} \\
\hline Step-index MMF without cladding & $\begin{array}{l}35 \mathrm{~nm} \mathrm{Ag} / 100 \mathrm{~nm} \\
\mathrm{SiO}_{2} / 180 \mathrm{~nm} \mathrm{WO}_{3} / \\
3 \mathrm{~nm} \mathrm{Pt}\end{array}$ & $2 \%$ & $8.7 \mathrm{~nm} / \%$ & -- & {$[71]$} \\
\hline Hetero-core structured SMF & $\begin{array}{l}25 \mathrm{~nm} \mathrm{Au} / 60 \mathrm{~nm} \\
\mathrm{Ti}_{2} \mathrm{O}_{5} / 5 \mathrm{~nm} \mathrm{Pd}\end{array}$ & $4 \%$ & $7 \mathrm{~nm} / \%$ & $15 \mathrm{~s}$ & {$[14]$} \\
\hline Hetero-core structured SMF & $\begin{array}{l}25 \mathrm{~nm} \mathrm{Au} / 60 \mathrm{~nm} \\
\mathrm{Ti}_{2} \mathrm{O}_{5} / 10 \mathrm{~nm} \mathrm{Pd}\end{array}$ & $4 \%$ & $7 \mathrm{~nm} / \%$ & $8 \mathrm{~s}$ & {$[73]$} \\
\hline $\begin{array}{l}\text { Step-index plastic-clad silica MMF } \\
\text { without cladding }\end{array}$ & $\mathrm{ZnO}_{0.6} \mathrm{Pd}_{0.4}(80 \mathrm{~nm})$ & $4 \%$ & $20 \mathrm{~nm} / \%$ & $1 \mathrm{~min}$ & {$[75]$} \\
\hline
\end{tabular}

The above examples demonstrated that the optical fiber SPR sensor has the advantages of high sensitivity and compact structure. However, the working wavelength is usually located around 600 $\mathrm{nm}$, resulting in a large fiber transmission loss compared with the window of $1550 \mathrm{~nm}$. Besides, it is needed and critical to accurately control the thicknesses of multi metallic films, which determine the sensing properties of the SPR sensor, so some expensive coating equipments is required.

\subsection{Other sensors}

Besides the above types of optical fiber hydrogen sensor, in recent years, many novel structures 
and principles have also been proposed and demonstrated for hydrogen concentration measurement.

In 2014, Y. Wang et al. [76] proposed a high-sensitive hydrogen sensing device based on selectively infiltrated $\mathrm{PCF}$ with Pt-loaded $\mathrm{WO}_{3}$ coating. As shown in Fig. 30, one air hole of PCF is filled with standard liquid with refractive index of 1.508 , by using the femtosecond laser-assisted selective infiltration technique, which can excite an embedded coupler together with the fiber core based on the light coupling between the core $\mathrm{LP}_{01} \underline{\text { mode }}$ and the liquid-waveguide $\mathrm{LP}_{11}$-like mode at resonant wavelengths. With Pt-loaded $\mathrm{WO}_{3}$ coating acting as the catalytic layer, hydrogen

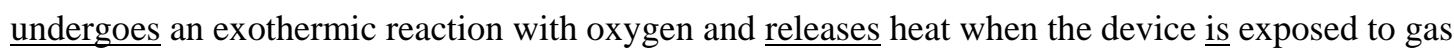
mixtures of air and hydrogen, which will then induce local temperature change in the PCF. Therefore, the resonant wavelength is extremely sensitive to hydrogen concentration due to the avoided crossing effect and the high thermal-optic coefficient of infiltrated liquid. As a result, a maximum wavelength shift of $98.5 \mathrm{~nm}$ is obtained with a 10-mm-long infiltrated PCF for $4 \%$ hydrogen concentration, and a hydrogen sensitivity of $32.3 \mathrm{~nm} / \%$ is achieved within the range of $1 \%-4 \%$. However, it should be noticed that the proposed hydrogen sensor exhibits a large temperature cross sensitivity as the selectively infiltrated PCF device is extremely sensitive to temperature. Thus, temperature calibration should be introduced in the practical applications to maintain a reasonably high measurement resolution of hydrogen concentration.

In 2015, X. Wu et al. [77] proposed a Pd-coated silica microfiber knot for hydrogen sensing, in which the silica microfiber was fabricated by a flame-heated taper-drawing process from standard SMF. It owns high fractional evanescent fields while maintaining low optical losses. Fig. 31 shows the schematic diagram of the Pd-coated microfiber knot resonator (MKR), in which an MKR is protruded out of an $\mathrm{MgF}_{2}$ substrate with a distance of $\sim 50 \mu \mathrm{m}$, and two fiber tapers are supported on 
the $\mathrm{MgF}_{2}$ substrate due to its low refractive index. In the coupling region, two microfibers are capable of attaching each other tightly via van der Waals and electrostatic attractive force. To collect optical signals from the MKR, another tapered microfiber is arranged adjacent to the freestanding end of the MKR to form a coupler with an overlap of several micrometers. For a robust sensing operation, the microfibers are also bound on the substrate using a UV curable fluoropolymer.
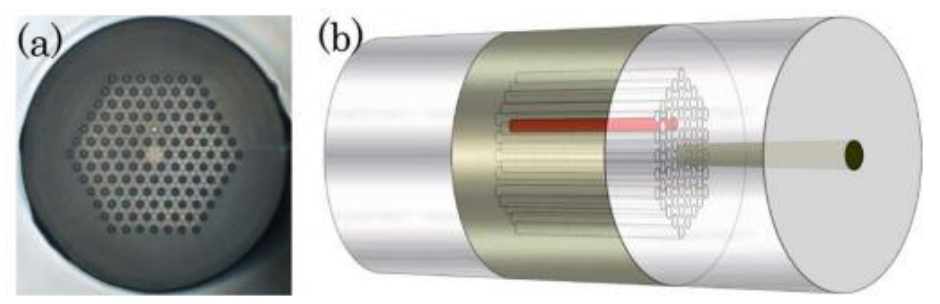

Fig. 30 Schematic probe structure and response of optical fiber hydrogen sensor based on resonant coupling

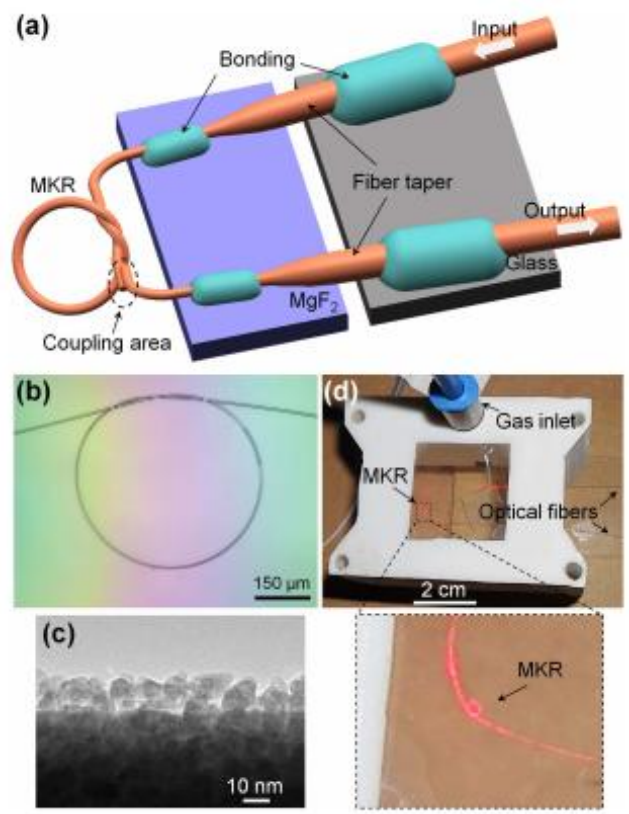

Fig. 31 Schematic probe structure of optical fiber hydrogen sensor based on microfiber knot resonator

In 2016, H. T. Yan et al. [78] demonstrated an integrated hydrogen sensor with Pd metallic grating fabricated on a fiber end-face, as shown in Fig. 32(a). The grating consists of three thin metal layers $\left(\mathrm{Au}, \mathrm{WO}_{3}\right.$, and $\left.\mathrm{Pd}\right)$ in stacks. The $\mathrm{WO}_{3} \underline{\text { is }}$ used as a waveguide layer between $\underline{\mathrm{Pd} \text { layer }}$ 
and layer. The Pd layer is etched by using a focused ion beam method to form a Pd metallic grating with period of $450 \mathrm{~nm}$. When hydrogen concentration is changed from $0 \%$ to $4 \%$, the resonant wavelength measured from the reflection will experience $28.10 \mathrm{~nm}$ spectral shift in the visible range (see Fig. 32(b)), with sensitivity of about $7.5 \mathrm{~nm} / \%$.

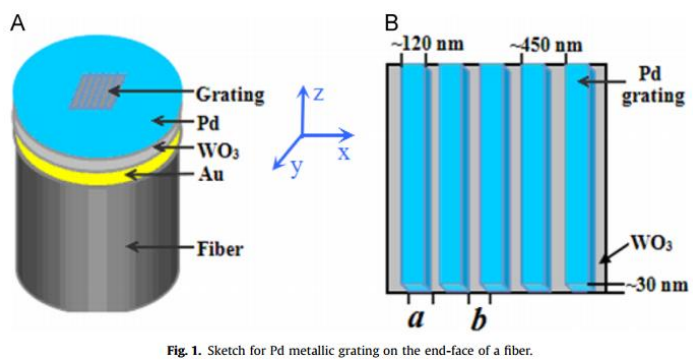

(a) Probe structure

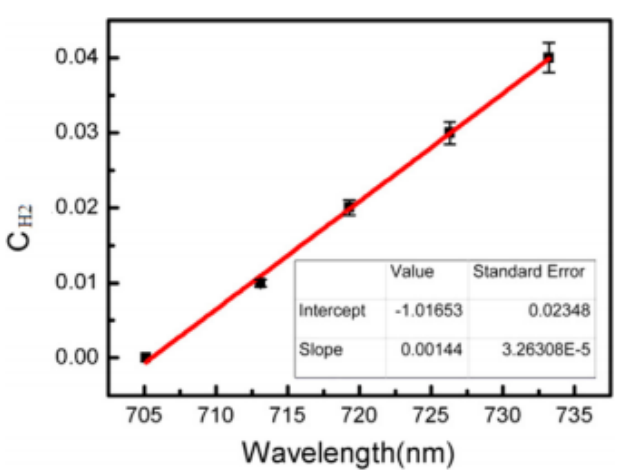

(b) Output response

Fig. 32 Schematic probe structure and response of optical fiber hydrogen sensor based on Pd metallic grating

\section{Comparison of Different Sensors}

From the above analyses, it is clear that many efforts have been attempted to develop sensitive film-based optical fiber sensors, either for single-point or multipoint hydrogen monitoring, and a variety of methods have been successfully demonstrated. According to the measurement method, optical fiber hydrogen sensors can be divided into four main types: intensity-based, fiber grating-based, interferometer-based, and surface plasmon resonance-based hydrogen sensors. Through comprehensive comparison of the performances of various optical fiber hydrogen sensors that shown in table 1 , table 2 , table 3 , and table 4 , it can be found that: Intensity-based sensors ranging from fiber tip to in-line fiber devices in general show simple structure and low cost, but the essential intensity detection method makes the sensor easily susceptible to the fluctuations of light $\underline{\text { source and fiber loss; FBG-based sensors with reflective head structures are noteworthy for remote }}$ monitoring and their unique advantage of multiplex property is suitable for distributed monitoring, 
but they usually require tapered/etched/polished processes to enhance sensitivity, which make them fragile and influence their long-term stability; LPG-based sensors are robust and easily reproducible, but the sensing head can only be transmission type and their fabrication costs are high; $\underline{\text { Interferometer-based sensors owns more flexible structure and high sensitivity, but their output }}$ $\underline{\text { spectrums are difficult to demodulate; Surface plasmon resonance-based hydrogen sensors present }}$ the highest sensitivity and response rate, but they require high-precision coating instruments. For easier comparison, the structural features and sensing performances of various hydrogen sensors are all summarized in Table 5.

Table 5. Performances comparison of different optical fiber hydrogen sensors

\begin{tabular}{|c|c|c|c|c|c|}
\hline Performances & $\begin{array}{l}\text { Intensity-based } \\
\text { sensors }\end{array}$ & $\begin{array}{l}\text { FBG-based } \\
\text { sensors }\end{array}$ & $\begin{array}{l}\text { LPG-based } \\
\text { sensors }\end{array}$ & $\begin{array}{l}\text { Interferometer-based } \\
\text { sensors }\end{array}$ & $\begin{array}{l}\text { SPR-based } \\
\text { sensors }\end{array}$ \\
\hline $\begin{array}{l}\text { Structural } \\
\text { complexity }\end{array}$ & Simple & $\begin{array}{l}\text { Relatively } \\
\text { simple }\end{array}$ & $\begin{array}{l}\text { Relatively } \\
\text { simple }\end{array}$ & Moderate & Complex \\
\hline Sensor cost & Low & Relatively low & Relatively high & $\begin{array}{l}\text { Relatively high but } \\
\text { can be improved }\end{array}$ & High \\
\hline Sensor size & Small & Small & Moderate & $\begin{array}{l}\text { Relatively large but } \\
\text { can be improved }\end{array}$ & Moderate \\
\hline $\begin{array}{l}\text { Fabrication } \\
\text { difficulty }\end{array}$ & Low & Low & Relatively high & Moderate & High \\
\hline Sensitivity & Low & Low & Moderate & Relatively high & High \\
\hline Precision & Low & Moderate & Moderate & Relatively high & High \\
\hline $\begin{array}{l}\text { Measurement } \\
\text { range }\end{array}$ & $\begin{array}{l}\text { Relatively } \\
\text { narrow }\end{array}$ & Wide & Restricted & Restricted & Moderate \\
\hline Response rate & Slow & Slow & Relatively slow & Moderate & Quick \\
\hline $\begin{array}{l}\text { Multiplexed } \\
\text { measurement }\end{array}$ & Unable & Able & Unable & Unable & Able \\
\hline $\begin{array}{l}\text { Mechanical } \\
\text { strength }\end{array}$ & Fragile & Fragile & High & $\begin{array}{l}\text { Depend on specific } \\
\text { structure }\end{array}$ & Moderate \\
\hline
\end{tabular}

In general, each type of hydrogen sensor introduced above has its own advantages and disadvantages. Meanwhile, their performances can be further improved, either using different $\underline{\text { metals or alloys as sensitive films, or resorting to advanced deposition techniques, and optimizing }}$ $\underline{\text { structures of sensing head used. In practical applications, different measurement methods can be }}$ 
selected according to actual needs.

\section{Existing Problems of Optical Fiber Hydrogen Sensor}

Optical fiber hydrogen sensor based on sensitive film has been widely developed, in which the film is worked as sensitive element and transducer for getting response and feedback of hydrogen concentration, optical fiber is employed to work as signal carrier, and different measurement methods are introduced for signal demodulation. Up to date, many types of sensor have been developed with different sensitive films. However, there still exist some common problems that needed to be resolved:

\subsection{Nonlinear output of hydrogen sensor}

In many cases, the relationship between sensor output and hydrogen concentration is nonlinear in the measurement range. For example: in [46], the measurement sensitivity for hydrogen concentration ranging from $0 \%$ to $1 \%$ is higher than the case ranging from $1 \%$ to $4 \%$ (see Fig. 33(a)); while in [76], it's just the opposite_(see Fig. 33(b)). This phenomenon may be due to the nonlinear relationship between hydrogen absorption induced physicochemical parameters variations of sensitive film, the saturated absorption of hydrogen in sensitive film with the increase of hydrogen concentration, or the essentially nonlinear output property of optical fiber sensor. To resolve this problem, one method is to select suitable doping material and doping ratio, another method is to $\underline{\text { select suitable measurement method and optimize its structural parameters. }}$ 


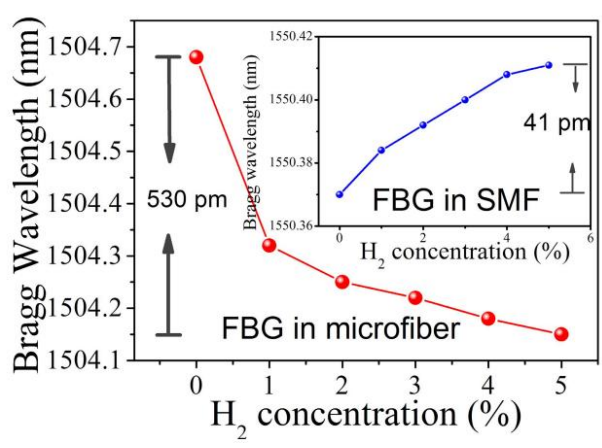

(a)

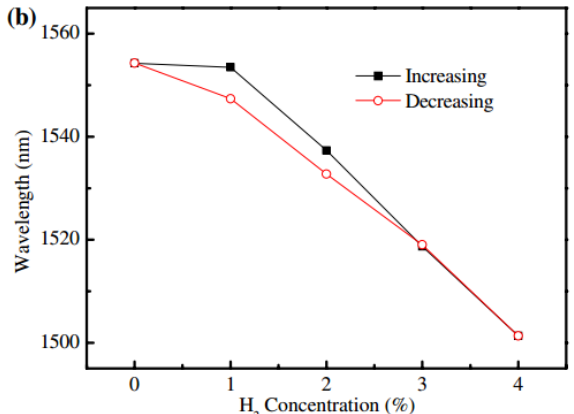

(b)

Fig. 33 Examples of nonlinear output of optical fiber hydrogen sensor, in which (a) is quoted from ref. [46] and (b) is quoted from ref. [76].

\subsection{Low-qualities of sensitive film}

The qualities of coated sensitive film include the uniformity, precisions of doping ratio and thickness, mechanical stability, and so on [9]. The first two cases will eventually influence the precision and sensitivity of hydrogen sensor, which can be improved by increase the technology $\underline{\text { level of coating process. In contrast, the latter one will affect the life of hydrogen sensor. To provide }}$ good repeatability to cyclic hydrogen changes and enhance stability of the hydrogen sensor, some $\underline{\text { transition metal oxides such as } \mathrm{TiO}_{2}} \underline{\mathrm{NiO}}_{x}$, and $\mathrm{WO}_{3} \underline{\text { are used. Besides, the mechanical stability will }}$ get worse and the response time will become long when sensitive film is too thick, but a thicker layer of sensitive film will generate a larger wavelength shift for the same hydrogen concentration, so it is also very critical to precisely choose the film thickness.

\subsection{Slow response rate}

The response time and recovery time of hydrogen sensor are generally high, which will hinder the real-time property of hydrogen detection, and decrease its potential for practical applications. But hydrogen sensing response rate is very important in some cases, such as nuclear power stations and aerospace vehicles. To reduce the response time, the first method is to increase the reaction velocity between hydrogen and sensitive film by reducing the size of sensitive particle, increasing the purity of $\underline{\mathrm{Pd}}$ or $\mathrm{WO}_{3}$, and optimizing the doping ratio [79]; the second method is to reduce the thickness of 
the coating; the third method is use $\mathrm{Pd}$ alloys (such as $\mathrm{Pd} / \mathrm{Ni}$ and $\mathrm{Pd} / \mathrm{Ti}$ ). However, it should be noted that the above proposed methods will also influence the measurement sensitivity of hydrogen concentration [80]. Therefore, these parameters should be properly chose according to different application requirements.

\subsection{Temperature disturbances}

For different surrounding temperatures, the physicochemical parameters of sensitive film and $\underline{\text { sensing properties of optical fiber sensor may be different, which will introduce uncertain }}$ measurement errors. Besides, for each measurement method, the sensor itself is also sensitive to temperature. For example: the temperature sensitivity of FBG can reach $10 \mathrm{pm} /{ }^{\circ} \mathrm{C}$; Taking a Pd-coated FBG for example, the Bragg wavelength can shift by only tens of picometers with the existence of hydrogen. However, the temperature sensitivity of FBG, in contrast, reaches $10 \mathrm{pm} /{ }^{\circ} \mathrm{C}$, which can possibly cause failure of hydrogen concentration detection. Particularly, the Sagnac $\underline{\text { interferometer has a high temperature sensitivity of } \sim 1 \mathrm{~nm} /{ }^{\circ} \mathrm{C} \text {. In addition, for different }}$ hydrogen sensors, the temperature sensitivity is changeable and can be decreased by designing

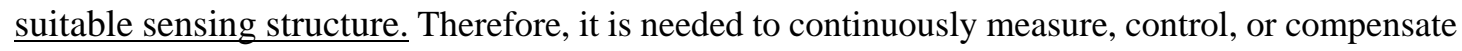
the ambient temperature in order to calibrate the sensor response.

\subsection{Humidity influences}

The humidity influences to hydrogen sensor have been rarely concerned by researchers. Actually, high ambient humidity has a bad effect on the sensor's sensitivity and response rate. The adsorbed $\mathrm{H}_{2} \mathrm{O}$ of sensitive film will reduce the diffusion rate of hydrogen atoms so that the hydrogen sensor's response time will be increased. Moreover, for Pd-based film, the adsorbed $\mathrm{H}_{2} \mathrm{O}$ will reduce the formation of $\mathrm{PdH}_{k}$, and then desensitize the hydrogen sensitive film towards the detection of 
hydrogen [81]. Therefore, it is needed to isolate the sensitive film from high humidity environment by using the water-phobic membrane such as PTFE Teflon [41].

\section{Future Prospects of Optical Fiber Hydrogen Sensor}

\section{$\underline{6.1 \text { New structure }}$}

In the aspect of structure, mainly refers to the structure of sensing head, the future aim can be $\underline{\text { summarized as simplification, miniaturization, and multiplexing. Firstly, simple structure in general }}$ can decrease the cost and fabrication complexity of sensor. Secondly, in some specific applications, $\underline{\text { such as aerospace vehicles, the sensor head should be small enough. To decrease the sensor size, one }}$ possible method is to use new microstructured fiber (namely photonic crystal fiber) with the reflective head structure. Finally, as hydrogen leakages may occur in different areas, to $\underline{\text { simultaneously detect hydrogen concentrations in the different areas with no additional detection }}$ equipment, a multiplexed hydrogen sensor is needed. However, at present, almost all of the existing optical fiber hydrogen sensors can only detect hydrogen concentration in one area. The primary results demonstrated that the FBG-based sensor [41] and SPR-based sensor [72] can be designed with cascaded structure, for detecting hydrogen concentrations in two different areas. Besides, it has been demonstrated that the multimode gratings have been used for temperature, strain, and chemical refractive index sensing [82-84], and have the potential for multiple parameters sensing [82]. Therefore, the multimode gratings have the potential for multipoint hydrogen concentration monitoring or temperature compensating. In addition, the refractive index sensitivity of etched fiber Bragg gratings inscribed in multimode fibers are higher than the one found at etched fiber Bragg grating inscribed in single-mode fibers, due to that greater multimode core diameter enables Bragg gratings to exhibit enhanced sensitivity without requiring further fiber diameter reduction [85]. 
However, it also means that usually a costly spectrum analyzer is needed to analyze the corresponding spectrum changes of multimode grating. In the future, it is still greatly needed to further develop low-cost, miniaturized, and multipoint sensing structure for constructing hydrogen monitoring network.

\section{$\underline{6.2 \text { New method }}$}

In the aspect of method, mainly refers to the demodulation method, the future aim can be $\underline{\text { summarized as high measurement sensitivity, wide measurement range, and good measurement }}$ precision. It may be possible to enhance the measurement sensitivity and the corresponding measurement range of sensor by introducing some new principles, such as slow light [86], whispering gallery mode (WGM) [87], and Vernier effect [88], into the sensing region, which have been demonstrated to increase the interaction effect between optical signal and measured medium. Besides, in order to improve the measurement precision, it is necessary to reduce and eliminate the influences of surrounding environment factors, such as temperature, humidity, and variation.

\section{$\underline{6.3 \text { New material }}$}

In the aspect of material, mainly refers to the sensitive film, the future aim can be summarized as $\underline{\text { rapid response rate, long-term stability, and good selectivity. At present, } \mathrm{Pd} \text { alloys using Ti and } \mathrm{Au}}$ have been utilized to reduce response time, and increase the stability of the hydrogen sensor. Besides, transition metal oxides, such as $\mathrm{TiO}_{2}, \mathrm{NiO}_{2}$, and $\mathrm{WO}_{3} \underline{\text { have been used to provide good }}$ repeatability to cyclic hydrogen changes and enhance stability of the sensor. However, very few $\underline{\text { studies have been done on the selectivity of hydrogen sensor. In addition, regardless of the }}$ measurement method used, the response time is still quite long (many seconds, and even minutes or hours in some cases). Therefore, further research investment on new sensitive material is required to 
address these issues.

\subsection{New technology}

In the aspect of technology, mainly refers to the coating and packaging technologies, the future aim can be summarized as simple operation, low cost, and good durability. Although many coating technology, including sol-gel method, magnetron sputtering method, and vacuum coating method, have been proposed for coating hydrogen sensitive film, but they still exist the problem of complex operation, high cost, or instability. So there is still a huge potential to develop the coating technology. Besides, the optical fiber hydrogen sensing head, which is mainly consisted of bare fiber, especially the core-exposed fiber, is relatively fragile and unstable. Considering the practical application of hydrogen sensor, a suitable and robust packaging process is needed to enhance sensor's durability.

\section{Conclusion}

In this paper, the most key developments of optical fiber hydrogen sensors over recent years were reported. General measurement principles based on $\mathrm{Pd}$ film and $\mathrm{WO}_{3}$ film have been firstly addressed and then different measurement methods relying on intensity, FBG, interferometer, and SPR have been presented. The advantages and disadvantages for each measurement method were also discussed. Finally, the existing problems and future research directions were outlined, which were of high relevance for optical fiber hydrogen sensing. Obviously, the readers who are interested in this field could not only see the unique properties and flexibilities in structural design of optical fiber hydrogen sensors, but also broaden their thoughts and burst out some new solutions to further exploit more novel optical fiber hydrogen sensors.

The review for the reported works and their corresponding results demonstrated that the optical hydrogen sensors have played very important roles in the hydrogen measurement fields and will 
produce a significant industrial value. Besides, much more design schemes of optical fiber hydrogen sensors will be proposed and much better sensing properties will be presented, along with the technology development of thin film deposition technology, which will then inspire promising prospective for thin film-based optical fiber sensors.

\section{Acknowledgments}

This work was supported in part by the National Science Foundation for Distinguished Young Scholars of China under Grant 61425003, the National Natural Science Foundation of China under

Grant 61273059, the Fundamental Research Funds for the Central Universities under Grant N140404021 and N150401001, the Liaoning Province Dr. started fund under Grant 201501087, and State Key Laboratory of Synthetical Automation for Process Industries under Grant 2013ZCX09.

\section{References:}

[1] S. E. Hosseini, M. A. Wahid. Hydrogen production from renewable and sustainable energy resources: Promising green energy carrier for clean development. Renewable \& Sustainable Energy Reviews, 2016, 57: 850-866.

[2] A. L. Bychkov, S. M. Korobeynikov, A. Y. Ryzhkina, Determination of the hydrogen diffusion coefficient in transformer oil. Technical Physics, 2011, 56 (3): 421-422.

[3] X. Bevenot, A. Trouillet, C. Veillas, H. Gagnaire, M. Clement. Hydrogen leak detection using an optical fibre sensor for aerospace applications. Sensors and Actuators B: Chemical, 2000, 
67(1-2): 57-67.

[4] P. Caumon, M. L. B Zulueta, J. Louyrette, S. Albou, C. Bourasseau, C. Mansilla. Flexible hydrogen production implementation in the French power system: Expected impacts at the French and European levels. Energy, 2015, 81: 556-562.

[5] D. A. Crowl, Y. D. Jo. The hazards and risks of hydrogen. Journal of Loss Prevention in the Process Industries, 2007, 20(2): 158-164.

[6] W. J. Buttner, M. B. Post, R. Burgess, C. Rivkin. An overview of hydrogen safety sensors and requirements. International Journal of Hydrogen Energy, 2011, 36(3): 2462-2470.

[7] T. Hübert, L. Boon-Brett, G. Black, U. Banach. Hydrogen sensors - A review. Sensors and Actuators B: Chemical, 2011, 157(2): 329-352.

[8] M. H. Yang, Z. Yang, J. X. Dai, D. Zhang. Fiber optic hydrogen sensors with sol-gel $\mathrm{WO}_{3}$ coatings. Sensors and Actuators B: Chemical, 2012, 166: 632-636.

[9] Y. Liu, Y. P. Chen, H. Song, G. Zhang. Characteristics of an optical fiber hydrogen gas sensor based on a palladium and yttrium alloy thin film. IEEE Sensors Journal, 2013, 13(7): 2699-2704.

[10] H. Song, Y. P. Chen, G. Zhang, Y. Liu, P. C. Huang, H. W. Zhao, M. H. Yang, J. X. Dai, Z. Li. Optical fiber hydrogen sensor based on an annealing-stimulated Pd-Y thin film. Sensors and Actuators B: Chemical, 2015, 216: 11-16.

[11] S. Masuzawa, S. Okazaki, Y. Maru, T. Mizutani. Catalyst-type-an optical fiber sensor for hydrogen leakage based on fiber Bragg gratings. Sensors and Actuators B: Chemical, 2015, 217: 151-157.

[12] Z. Yang, M. Zhang, Y. B. Liao, Q. Tian, Q. S. Li, Y. Zhang, Z. Zhuang. Extrinsic Fabry-Perot 
interferometric optical fiber hydrogen detection system. Applied Optics, 2010, 49(15): 2736-2740.

[13] M. C. Navarrete, N. Diaz-Herrera, A. Gonzalez-Cano, O. Esteban. Surface plasmon resonance in the visible region in sensors based on tapered optical fibers. Sensors and Actuators B: Chemical, 2014, 190: 881-885.

[14] A. Hosoki, M. Nishiyama, H. Igawa, A. Seki, Y. Choi, K. Watanabe. A surface plasmon resonance hydrogen sensor using $\mathrm{Au} / \mathrm{Ta} 2 \mathrm{O} / \mathrm{Pd}$ multi-layers on hetero-core optical fiber structures. Sensors and Actuators B: Chemical, 2013, 185: 53-58.

[15] N. Javahiraly. Review on hydrogen leak detection: comparison between fiber optic sensors based on different designs with palladium. Optical Engineering, 2015, 54(3): 030901.

[16] S. K. Gullapalli, R. S. Vemuri, C. V. Ramana, Structural transformation induced changes in the optical properties of nanocrystalline tungsten oxide thin film. Applied Physical Letters, 2010, 96(17): 171903.

[17] H. D. Zheng, J. Z. Ou, M. S. Strano. Nanostructured tungsten oxide - properties, synthesis, and applications. Advanced Functional Materials, 2011, 21(12): 2175-2196.

[18] H. Shanak, H. Schmitt, J. Nowoczin. Effect of Pt-catalyst on gasochromic $\mathrm{WO}_{3}$ films: optical, electrical and AFM investigations. Solid State Ionics, 2004, 171(1-2): 99-106.

[19] A. Boudibaa, P. Rousseld, C. Zhanga, M. G. Oliviera, R. Snydersb, M. Debliquy. Sensing mechanism of hydrogen sensors based on palladium-loaded tungsten oxide $\left(\mathrm{Pd}-\mathrm{WO}_{3}\right)$. Sensors and Actuators B: Chemical, 2013, 187: 84-93.

[20] J. Z. Ou, M. H. Yaacoba, J. L. Campbellb, M. Breedona, K. Kalantar-zadeha, W. Wlodarski. H$_{2}$ sensing performance of optical fiber coated with nano-platelet $\mathrm{WO}_{3}$ film. Sensors and 
Actuators B: Chemical, 2012, 166: 1-6.

[21] M. Shibuya, M. Miyauchi. Efficient electrochemical reaction in hexagonal $\mathrm{WO}_{3}$ forests with a hierarchical nanostructure. Chemical Physics Letters, 2009, 473(1-3): 126-130.

[22] M. H. Yang, Z. Li, J. X. Dai, Z. Yang, Y. Zhang, Z. Zhuang. Comparison of optical fiber Bragg grating hydrogen sensors with Pd-based thin films and sol-gel $\mathrm{WO}_{3}$ coatings. Measurement Science and Technology, 2013, 24(9): 094009.

[23] M. Tabib-Azar, B. Sutapun, R. Petrick, A. Kazemi. Highly sensitive hydrogen sensors using palladium coated fiber optics with exposed cores and evanescent field interactions. Sensors and Actuators B: Chemical, 1999, 56(1-2): 158-163.

[24] S. Sekimoto, H. Nakagawa, S. Okazaki, K. Fukuda, S. Asakura, T Shigemori, S. Takahashi. A fiber-optic evanescent-wave hydrogen gas sensor using palladium-supported tungsten oxide. Sensors and Actuators B: Chemical, 2000, 66: 142-145.

[25] J. Villatoro, A. Diez, J. L. Cruz, M. V. Aiidrts. Highly sensitive optical hydrogen sensor using circular Pd-coated singlemode tapered fibre. Electronics Letters, 2001, 37(16): 1011-1012.

[26] J. Villatoro, A. Díez, J. L. Cruz, M. V. Andrés. In-line highly sensitive hydrogen sensor based on palladium-coated single-mode tapered fibers. IEEE Sensors Journal, 2003, 3(4): 533-537.

[27] K. T. Kim, H. S. Song, J. P. Mah, K. B. Hong, K. Im, S. J. Baik, and Y. I. Yoon. Hydrogen sensor based on palladium coated side-polished single-mode fiber. IEEE Sensors Journal, 2007, 7(12): 1767-1771.

[28] M. H. Yang, H. L. Liu, D. S. Zhang, X. L. Tong. Hydrogen sensing performance comparison of $\mathrm{Pd}$ layer and $\mathrm{Pd} / \mathrm{WO}_{3}$ composite thin film coated on side-polished single - and multimode fibers. Sensors and Actuators B: Chemical, 2010, 149(1): 161-164. 
[29] M. A. Butler. Fiber optic sensor for hydrogen concentration near the explosive limit. Journal of the Electrochemical Society, 1991, 138(9): 46-47.

[30] Y. Liu, Y.P. Chen, H. Song, G. Zhang. Modeling analysis and experimental study on the optical fiber hydrogen sensor based on Pd-Y alloy thin film. Review of Scientific Instruments, 2012, 83(7): 075001.

[31] Z. Li, M. H. Yang, J. X. Dai, G. P. Wang, C. J. Huang, J. G. Tang, W. B. Hu, H. Song, P. C. Huang. Optical fiber hydrogen sensor based on evaporated $\mathrm{Pt} / \mathrm{WO}_{3}$ film. Sensors and Actuators B: Chemical, 2015, 206: 564-569.

[32] T. Mak, R.J. Westerwaal, M. Slaman, H. Schreuders, A.W. van Vugt, M. Victoria, C. Boelsma, B. Dam. Optical fiber sensor for the continuous monitoring of hydrogen in oil. Sensors and Actuators B: Chemical, 2014, 190: 982-989.

[33] K. S. Park, Y. H. Kim, J. B. Eom, S. J. Park, M. S. Park, J. H. Jang, B. H. Lee, Compact and multiplexible hydrogen gas sensor assisted by self-referencing technique. Optics Express, 2011, 19(19): 18190-18198.

[34] S. J. Tang, B. Zhang, Z. Li, J. X. Dai, G. P. Wang, M. H. Yang. Self-compensated microstructure fiber optic sensor to detect high hydrogen concentration. Optics Express, 2015, 23(17): 22826-22835.

[35] B. Sutapun, M. Tabib-Azar, A. Kazemi. Pd-coated elastooptic fibre optic Bragg grating sensors for multiplexed hydrogen sensing. Sensors and Actuators B: Chemical, 1999, 60(1): 27-34.

[36] J. X. Dai, M. H. Yang, Y. Chen, K. Cao, H. S. Liao, P. C. Zhang. Side-polished fiber Bragg grating hydrogen sensor with $\mathrm{WO}_{3}$-Pd composite film as sensing materials. Optics Express, 2011, 19(7): 6141-6148. 
[37] J. Jiang, G. M. Ma, C. R. Li, H. T. Song, Y. T. Luo, H. B. Wang. Highly sensitive dissolved hydrogen sensor based on side-polished fiber Bragg grating. IEEE Photonics Technology Letters, 2015, 27(13): 1453-1456.

[38] J. X. Dai, M. H. Yang, X. Yu, K. Cao, J. S. Liao. Greatly etched fiber Bragg grating hydrogen sensor with Pd/Ni composite film as sensing material. Sensors and Actuators B: Chemical, 2012, 174: 253-257.

[39] J. X. Dai, M. H. Yang, Z. Yang, Z. Li, Y. Wang, G. P. Wang, Y. Zhang, Z. Zhuang. Enhanced sensitivity of fiber Bragg grating hydrogen sensor using flexible substrate. Sensors and Actuators B: Chemical, 2014, 196: 604-609.

[40] J. X. Dai, M. H. Yang, X. Yu, H. Lu. Optical hydrogen sensor based on etched fiber Bragg grating sputtered with Pd/Ag composite film. Optical Fiber Technology, 2013, 19: 26-30.

[41] L. Coelho, J. M. M. M. DE Almeida, J. L. Santos, D. Viegas. Fiber optic hydrogen sensor based on an etched Bragg grating coated with palladium. Applied Optics, 2015, 54(35): $10342-10348$.

[42] M. H. Yang, G. P. Wang, J. X. Dai, Z. Yang, Z. Li, Y. Wang, Y. Zhang, Z. Zhuang. Fiber Bragg grating sensors with Pt-loaded $\mathrm{WO}_{3}$ coatings for hydrogen concentration detection down to 200ppm. Measurement Science and Technology, 2014, 25: 114004.

[43] J. X. Dai, M. H. Yang, Z. Yang, Z. Li, Y. Wang, G. P. Wang, Y. Zhang, Z. Zhuang. Performance of fiber Bragg grating hydrogen sensor coated with Pt-loaded $\mathrm{WO}_{3}$ coating. Sensors and Actuators B: Chemical, 2014, 190: 657-663.

[44] J. M. Karanja, Y. T. Dai, X. Zhou, B. Liu, M. H. Yang. Micro-structured femtosecond laser assisted FBG hydrogen sensor. Optics Express, 2015, 23(24): 31034-31042. 
[45] S. Silva, L. Coelho, J. M. Almeida, O. Frazão, J. L. Santos, F. X. Malcata, M. Becker, M. Rothhardt, H. Bartelt. $\mathrm{H}_{2}$ sensing based on a Pd-coated tapered-FBG fabricated by DUV femtosecond laser technique. IEEE Photonics Technology Letters, 2013, 25(4): 401-403.

[46] Z. P. Yu, L. Jin, L. J. Chen, J. Li, Y. Ran, B. O. Guan. Microfiber Bragg grating hydrogen sensors. IEEE Photonics Technology Letters, 2015, 27(24): 2575-2578.

[47] G. M. Ma, C. R. Li, Y. T. Luo, R. D. Mu, L. Wang. High sensitive and reliable fiber Bragg grating hydrogen sensor for fault detection of power transformer. Sensors and Actuators B: Chemical, 2012, 169: 195-198.

[48] G. M. Ma, C. R. Li, Y. T. Luo, R. D. Mu, J. Jiang. Fiber Bragg grating sensor for hydrogen detection in power transformers. IEEE Transactions on Dielectrics and Electrical Insulation, 2014, 21(1): 380-385.

[49] G. M. Ma, J. Jiang, R. Li, H. T. Song, Y. T. Luo, H. B. Wang. Pd/Ag coated fiber Bragg grating sensor for hydrogen monitoring in power transformers. Review of Scientific Instruments, 2015, 86: 045003.

[50] A. Trouillet, E. Marin, C. Veillas. Fibre gratings for hydrogen sensing. Measurement Science and Technology, 2006, 17(5): 1124-1128.

[51] X. T. Wei, T. Wei, H. Xiao, Y. S. Lin. Nano-structured Pd-long period fiber gratings integrated optical sensor for hydrogen detection. Sensors and Actuators B: Chemical, 2008, 134: 687-693.

[52] Y. H. Kim, M J. Kim, B. S. Rho, M. S. Park, J. H. Jang, B. H. Lee. Ultra sensitive fiber-optic hydrogen sensor based on high order cladding mode. IEEE Sensors Journal, 2011, 11(6): $1423-1426$. 
[53] Y. Zhao, X. G. Li, L. Cai, Y. Yang. Refractive index sensing based on photonic crystal fiber interferometer structure with up-tapered joints. Sensors and Actuators B: Chemical, 2015, 221: 406-410.

[54] Y. H. Kim, M J. Kim, B. S. Rho, K. H. Kwack, B. H. Lee. Mach-Zehnder interferometric hydrogen sensor based on a single mode fiber having core structure modification at two sections. Sensors and Actuators B: Chemical, 2011, 11(6): 1423-1426.

[55] M. Wang, M. H. Yang, J. Cheng, J. X. Dai, M. W. Yang, D. N. Wang. Femtosecond laser fabricated micro Mach-Zehnder interferometer with Pd film as sensing materials for hydrogen sensing. Optics Letters, 2012, 37(11): 1940-1942.

[56] M. Wang, D. N. Wang, M. H. Yang, J. Cheng, J. Y. Li. In-line Mach-Zehnder interferometer and FBG with Pd film for simultaneous hydrogen and temperature detection. Sensors and Actuators B: Chemical, 2014, 202: 893-896.

[57] F. Zhou, S. J. Qiu, W. Luo, F. Xu, Y. Q. Lu. An all-fiber reflective hydrogen sensor based on a photonic crystal fiber in-line interferometer. IEEE Sensors Journal, 2014, 14(4): 1133-1136.

[58] T. Y. Hu, D. N. Wang, M. Wang, Z. Li, M. H. Yang. Miniature hydrogen sensor based on fiber inner cavity and Pt-doped $\mathrm{WO}_{3}$ coating. IEEE Photonics Technology Letters, 2014, 26(14): $1458-1461$.

[59] F. X. Gu, G. Q. Wu, H. P. Zeng. Hybrid photon-plasmon Mach-Zehnder interferometers for highly sensitive hydrogen sensing. Nanoscale, 2015, 7, 924-929.

[60] Z. P. Yu, L. Jin, L. P. Sun, J. Li, Y. Ran, B. O. Guan. Highly sensitive fiber taper interferometric hydrogen sensors. IEEE Photonics Journal, 2016, 8(1): 6800309.

[61] M. Wang, M. H. Yang, J. Cheng, G. L. Zhang, C. R. Liao, D. N. Wang. Fabry-Pérot 
interferometer sensor fabricated by femtosecond laser for hydrogen sensing. IEEE Photonics Technology Letters, 2013, 25(8): 713-716.

[62] Y. Wang, M. H. Yang, G. L. Zhang, J. X. Dai, Y. Zhang, Z. Zhuang, W. B. Hu. Fiber optic hydrogen sensor based on Fabry-Perot interferometer coated with sol-gel $\mathrm{Pt} / \mathrm{WO}_{3}$ coating. Journal of Lightwave Technology, 2015, 33(12): 2530-2534.

[63] C. B. Yu, Li Liu, X. X. Chen, Q. F. Liu, Y. Gong. Fiber-optic Fabry-Perot hydrogen sensor coated with Pd-Y film. Photonics Sensors, 2015, 5(2): 142-145.

[64] Y. Kim, T. K. Noh, Y. W. Lee, E. S. Kim, B. S. Shin, S. M. Lee. Fiber-optic hydrogen sensor based on polarization-diversity loop interferometer. Journal of the Korean Physical Society, 2013, 62(4): 575-580.

[65] Y. H. Yang, F. L. Yang, H. Wang, W. Yang, W. Jin. Temperature-insensitive hydrogen sensor with polarization-maintaining photonic crystal fiber-based Sagnac interferometer. Journal of Lightwave Technology, 2015, 33(12): 2566-2571.

[66] B. Xu, C. L. Zhao, F. Yang, H. P. Gong, D. N. Wang, J. X. Dai, M. H. Yang. Sagnac interferometer hydrogen sensor based on panda fiber with Pt-loaded $\mathrm{WO}_{3} / \mathrm{SiO}_{2}$ coating. Optics Letters, 2016, 41(7): 1594-1597.

[67] H. H. Nguyen, J. Park, S. Kang, M. Kim. Surface plasmon resonance: a versatile technique for biosensor applications. Sensors, 2015, 15(5): 10481-10510.

[68] X. Bevenot, A. Trouillet, C. Veillas, H. Gagnaire, M. Clement. Surface plasmon resonance hydrogen sensor using an optical fibre. Measurement Science and Technology, 2002, 13(1): 118-124.

[69] C. Perrotton, N. Javahiraly, Slaman, B. Dam, P. Meyrueis. Fiber optic surface plasmon 
resonance sensor based on wavelength modulation for hydrogen sensing. Optics Express, 2011, 19(23): A1175-A1183.

[70] C. Perrotton, R. J. Westerwaal, N. Javahiraly, M. Slaman, H. Schreuders, B. Dam, P. Meyrueis. A reliable, sensitive and fast optical fiber hydrogen sensor based on surface plasmon resonance. Optics Express, 2013, 21(1): 382-390.

[71] X. G. Wang, Y. K. Tang, C. D. Zhou, B. Liao. Design and optimization of the optical fiber surface plasmon resonance hydrogen sensor based on wavelength modulation. Optics Communications, 2013, 298: 88-94.

[72] X. G. Wang, Y. K. Tang, C. D. Zhou, B. Liao. Theoretical investigation of a dual-channel optical fibre surface plasmon resonance hydrogen sensor based on wavelength modulation. Measurement Science and Technology, 2013, 24: 065102.

[73] A. Hosoki, M. Nishiyama, H. Igawa, A. Seki, K. Watanabe. A hydrogen curing effect on surface plasmon resonance fiber optic hydrogen sensors using an annealed $\mathrm{Au} / \mathrm{Ta} 2 \mathrm{O} 5 / \mathrm{Pd}$ multi-layers film. Optics Express, 2014, 22(15): 18556-18563.

[74] B. D. Gupta. Surface plasmon resonance-based fiber-optic hydrogen gas sensor. Applied Optics, 2015, 54(5): 1032-1040.

[75] R. Tabassum, B. D. Gupta. Fiber optic hydrogen gas sensor utilizing surface plasmon resonance and native defects of zinc oxide by palladium. Journal of Optics, 2016, 18: 015004.

[76] Y. Wang, D. N. Wang, F. Yang, Z. Li, M. H. Yang. Sensitive hydrogen sensor based on selectively infiltrated photonic crystal fiber with Pt-loaded $\mathrm{WO}_{3}$ coating. Optics Letters, 2014, 39(13): 3872-3875.

[77] X. Wu, F. X. Gu, H. P. Zeng. Palladium-coated silica microfiber knots for enhanced hydrogen 
sensing. IEEE Photonics Technology Letters, 2015, 27(11): 1228-1231.

[78] H. T. Yan, X. Y. Zhao, C. Zhang, Q. Z Li, J. X. Cao, D. F. Han, H. Hao, M. Wang. A fast response hydrogen sensor with Pd metallic grating onto a fiber's end-face. Optics Communications, 2016, 359: 157-161.

[79] D. Monzón-Hernández*, D. Luna-Moreno, D. Martínez-Escobar. Fast response fiber optic hydrogen sensor based on palladium and gold nano-layers. Sensors and Actuators B: Chemical, 2009, 136(2): 562-566.

[80] Y. H. Kim, M. J. Kim, M. S. Park, J. H. Jang, B. H. Lee. Hydrogen sensor based on a palladium-coated long-period fiber grating pair. Journal of the Optical Society of Korea, 2008, 12(4): 221-225.

[81] Z. Zhao, M. Knight, S. Kumar, E.T. Eisenbraun, M.A. Carpenter. Humidity effects on Pd/Au-based all-optical hydrogen sensors, Sensors and Actuators B: Chemical, 2008, 129: 726-733.

[82] T. V. Djambova, T. Mizunami. Simultaneous sensing of temperature and displacement using a multimode fiber Bragg grating. Japanese Journal of Applied Physics, 2000, 39(3B): $\underline{1566-1570 .}$

[83] R. M. Cazo, O. Lisboa, H. T. Hattori, et al. Experimental analysis of reflected modes in a multimode strained grating, Microwave and Optical Technology Letters, 2001, 28(1): 4-8.

[84] X. Z. Sang, C. X. Yu, B. B. Yan, et al. Experimental investigation on chemical sensor based on a multimode fiber Bragg grating. Microwave and Optical Technology Letters, 2006, 48(9): 1739-1741.

[85] J. F. Kuhne, V. de Oliveira, H. J. Kalinowski, et al. Refractive index sensitivity of fiber Bragg 
grating inscribed in a multimode fiber. 2015 SBMO/IEEE MTT-S International Microwave and Optoelectronics Conference (IMOC), Germany, Nov. 03-06, 2015.

[86] Y. N. Zhang, Y. Zhao, Q. Wang. Multi-component gas sensing based on slotted photonic crystal waveguide, Sensors and Actuators B: Chemical, 2013, 184: 179-188.

[87] G. C. Righini, Y. Dumeige, P. Feron, et al. Whispering gallery mode microresonators: Fundamentals and Applications, 2011, 34(7): 435-488.

[88] M. Quan, J. Tian, Y. Yao. Ultra-high sensitivity Fabry-Perot interferometer gas refractive index fiber sensor based on photonic crystal fiber and Vernier effect. Optics Letters, 2015, 40(21): 4891-4894. 